\title{
Tardive dyskinesia revisited-a clinical management priority perspective: a voyage into high dose buspirone part B
}

\begin{abstract}
Management of tardive dyskinesia : abstract: section I
We discuss several major related and integrated issues in this two-part series of papers on tardive dyskinesia (TD). In this, the second paper, Part B, the management and mechanisms are emphasized; in Part A the diagnosis and assessment of tardive dyskinesia was discussed. In this Part B series of articles we examine several special important priorities in this condition associated with sometimes permanent involuntary abnormal movements associated with the neuroleptic drugs. We particularly examine the management of this enormously important condition. After the diagnosis and assessment of TD, comes the clinical approach to management and the options and theories behind that approach. There remain no approved medications for the management of tardive dyskinesia. Therefore, all treatments are "out of labeling". The purpose of this paper is to shed light on high dose buspirone treatment, originally described by the author in $1989,{ }^{1}$ and which after more than a quarter century requires re-evaluation as it still appears, in the author's opinion, to be the logical and most appropriate management for TD.
\end{abstract}

A major issue focuses, on the updated experience of more than a quarter century with generally almost completely positive effects of high-dose buspirone (HDB) treatment of tardive dyskinesia (TD) and the next issue provides an important, major theoretical demonstration of the mechanism of tardive dyskinesia. The dopamine 2 or 2-3 supersensitivity hypothesis as a cause of TD is strongly supported by HDB. In Part B, the issue of choice of medication for psychosis and related medical conditions becomes pertinent. The choices relate to the newer second generation atypical neuroleptics (SGAs) compared with the older typical, first generation neuroleptics (FGAs). The generally more expensive SGA drugs have become far the most used anti-psychotic agents in wealthy countries such as the United States, because of their efficacy and ostensible safety. Certain maxims are mentioned.

Keywords: aims, atypical neuroleptics, blind study, buspirone, clinical, dopamine, d1, d2, d3, double-blind, high-dose buspirone, history, mechanism, neppe, neuroleptics, partial agonism, receptor, single-blind, straw, supersensitivity, symptoms, tardive dyskinesia, tardive dystonia
Volume 6 Issue 2 - 2016

\author{
Vernon M Neppe ${ }^{1,2,3}$ \\ 'Director, Pacific Neuropsychiatric Institute and Exceptional \\ Creative Achievement Organization, USA \\ ${ }^{2}$ Executive Director and Distinguished Professor, Exceptional \\ Creative Achievement Organization, USA \\ ${ }^{3}$ Adj.Professor, Department of Neurology and Psychiatry, St. \\ Louis University, USA
}

\begin{abstract}
Correspondence: Vernon M Neppe, Director, Pacific Neuropsychiatric Institute and Exceptional Creative Achievement Organization, Seattle, Washington, USA, Tel 206 527 6289, Email psyche@pni.org
\end{abstract}

Received: June 16,2016 | Published: June 30, 2016

\section{Perspective to a pertinent history of neuroleptic use : section 2}

The very serious, prescription induced condition of tardive dyskinesia (TD) is associated with abnormal involuntary movements. TD is caused by or aggravated by so- called "neuroleptic" drugs. Usually used to manage psychotic conditions, as well as nausea and acid reflux, and sometimes adjunct medications to depression. The onset of TD can be during exposure to neuroleptics, or within a month of withdrawal (or two months if it was a depot neuroleptic). TD manifests differently and tardive syndromes may persist for months or years after drug withdrawal and in some patients, the TD is irreversible., ${ }^{2,3}$

An increased incidence of undiagnosed involuntary movements began in the $1950 \mathrm{~s}$ after the development of antipsychotic medication. The first neuroleptic (so-called because of their special, specific "neurolepsis"4 effects on experimental animals ${ }^{5-7}$ ) was chlorpromazine. ${ }^{8}$ It was synthesized in December 1951 in RhônePoiulenc Labs in France, ${ }^{8}$ and remarkably became available for prescription in France by November $1952 .{ }^{8}$ It revolutionized the treatment of psychosis. However, more involuntary movements began to be reported but they were not diagnosed as due to any drug because there always had been prior reports of a much less common condition called "spontaneous" dyskinesia (SD). SD when just based on symptoms are indistinguishable from TD, but had been rare. So when more movements began to arise, they were apparently regarded possibly as these spontaneous" dyskinesia. ${ }^{9}$ Ironically, in $1955,{ }^{10}$ chlorpromazine was reported to improve these movements after an initial 1954 report ${ }^{11}$ ! This, in retrospect, was likely a temporary phenomenon sometimes seen with increases in doses, though the changes over long time periods would ultimately worsen the condition.

In February1958, Bert Hermans at the Janssen Laboratories in Beerse, Belgium invented the very powerful neuroleptic Haloperidol. ${ }^{12,13}$ That, even more so revolutionized the treatment of psychosis because it was very potent and was therefore became the most popular agent. It had profound clinical effects, ${ }^{14,15}$ but, in my opinion, it became and remains possibly the greatest cause of TD ever. Over many years to the present, about seventy neuroleptics have been developed. Each have slightly different properties, and may variably induce TD more or less than other neuroleptic compounds. Neuroleptics remain predominantly used for psychosis of any kind: This is often schizophrenia, but their approved uses extends to mania and bipolar illness, in prophylaxis of psychosis, in gastroenterology as in oesophageal reflux, in geriatrics, and more recently, as adjunct to anxiety and depression. They remain extraordinarily important potent drugs and can save lives and provide the realization of success 
in these conditions, but also they are problematic because of the TD, particularly. Not surprisingly, there are no approved medications for tardive dyskinesia. Therefore, all treatments are by definition "out of labeling" and officially innovative. But, tardive dyskinesia conventionally remains as regarded as an "incurable condition". The author regards such intractability as incorrect, because high-dose buspirone treatment, appears extremely promising. This is important because there are no other drugs that have been demonstrated to have anything but a marginal effect on the condition.

Applying the label of an "incurable condition" to TD may be incorrect: The author regards such intractability as potentially untrue in many cases, because since his report in December 1989 in the Lancet of high dose buspirone (HDB) markedly alleviating the TD. ${ }^{1}$ The treatment remains extremely promising, even more so today. There is now profound support for HDB when applying not only clinical experience but also the animal, human, and biochemical model. Moreover, the drug in those high does appears safe. HDB is important because, even today, there are no other drugs that have been demonstrated to have anything but an extended marginal effect on the condition. A further preliminary theoretical postulate is put forward that the tardive dyskinesia effects are predominantly due to Dopamine 2 (or 3 as it is part of the same receptor family). If this were so, dopamine blocking drugs that are less selective (acting on dopamine 1, as well) should produce less risk of tardive dyskinesia than selective dopamine 2 (or 3) neuroleptic agents. In Part 1, Section 1 we discussed the broader features of tardive dyskinesia, and in Section 2, the various scales to more precisely measure TD, including particularly the STRAW scale developed by the author. This paper, Part B, now continues with discussing management.

\section{High dose buspirone treatment in tardive dyskinesia: Section $3^{d}$}

${ }^{\mathrm{d}}$ Vernon M Neppe MD, PhD, Pacific Neuropsychiatric Institute, Seattle, WA

\section{Abstract}

The third section focuses, on the updated experience of more than a quarter century with generally almost completely positive effects of high-dose buspirone (HDB) treatment of tardive dyskinesia (TD).

We focus for the first time, on the updated experience of more than a quarter century with high-dose buspirone (HDB) treatment of tardive dyskinesia (TD). The consistent and generally almost completely positive effect of HDB in doses like $120 \mathrm{mg}$ to $180 \mathrm{mg}$ daily strongly supports its ostensible use, value and major impact in this condition. There is an important historical background to high dose buspirone. Clearly safety issues are pertinent: Buspirone in high doses provisionally appears safe. An important issue here is how meaningful clinical experience is, even though many academics regard doubleblind studies as the only empirical method to understand drugs, and when not to perform such studies. Because of its importance, an approach is given to the management by a clinical question and answer series on high-dose buspirone in TD.

Part 1: The history of high dose buspirone in the treatment of tardive dyskinesia

In December 1989 in the Lancet Journal, I first reported the use of high dose buspirone to treat tardive dyskinesia. ${ }^{1}$ I discussed in detail the first reported case and also the mechanisms, ${ }^{16}$ in Chapter 12 of the book, Cry The Beloved Mind: A Voyage of Hope. I also discussed in detail the neuropharmacology of buspirone in another older book
Innovative Psycho pharmacotherapy (First and Second editions). ${ }^{17,18}$ We thereafter used high dose buspirone, with appropriate informed consent, on several patients. The responses were profound. Indeed, the treatment was so successful and so valuable, that we even at that point already could not ethically justify a placebo-controlled double-blind study: It was not needed because the results were so startlingly obvious and overt, and the medication ostensibly so benign. Moreover, the key to greatest success with buspirone is appropriate dosage. We replicated the original report in a single blind study at Washington University in St Louis. ${ }^{19}$ We, the researchers, chose a single blind study because at that point, the management was so striking we deemed depriving patients of the active medications to be inappropriate. However, the patients did not know what dose they were receiving.

\section{Part 2: Efficacy}

I see far more tardive dyskinesia than most clinicians, even in neuropsychiatry and behavioral neurology, because patients with TD or their clinicians seek me out for consultation. I am also consulted forensically, adding to this pool of patients.

Consequently, I have seen significant numbers clinically, besides the literature reviews that I've looked at (Table 3A).

Table 3A High-dose buspirone treatment of tardive dyskinesia (TD).

a. Buspirone dose for TD is usually $120 \mathrm{mg}$ - 300mg in our experience

b. Neppe postulated at $120 \mathrm{mg}$ /day buspirone becomes a dopamine partial agonist (critical) ${ }^{1}$

c. This is the postulated dopamine partial agonist dose in TD patients. ${ }^{1,20,21}$

d. Buspirone data now suggest D1-D4 effects ${ }^{22-26}$

This treatment, high dose buspirone, is out-of-labeling, but I have found it over the past quarter century to be consistently far and away the most successful treatment for TD and IMHO it has been greatly under-utilized. With the advent of generics, buspirone is affordable, though it's difficult locating any dose size but the $15 \mathrm{mg}$ today, and if generic is used, the same consistent generic should be used (e.g., Teva). Besides the publications, I also presented these findings at conferences and numerous different grand rounds and lectures. $1,17,20,21,27-29$

Because this management is apparently clinically significant, I also chose to describe this treatment as one of five important findings in my "autobiographical sketch" for the CINP's "Leading Psychopharmacologists of the Twentieth Century". ${ }^{30}$

I also presented our findings at conferences and in numerous different grand rounds and lectures.

\section{Part 3: My patient experience}

Our experience now covers the last 26years. I will say this: I have received referrals for tardive dyskinesia from all around the USA, and have consulted forensically on TD as well. Yet, I have never seen a failed treatment over this time, or heard of one, provided that the appropriate high dosage of buspirone has been attained and provided the expectation is not one of full recovery, although most of the time the difference is profound (profound in a mild case is still profound relative to that case). Every one of our cases have been carefully monitored using an objective scoring evaluation called the STRAW that I developed specifically for tardive dyskinesia. As indicated, the STRAW is the only rating scale that measures both Time and Severity of the dyskinesia, applying several measures each on a 0 
to 10 scale. ${ }^{11,17,20,21,27,28}$ Additionally, we also use several other tests for comparison that are less sensitive (e.g., AIMS, SCT-Hans, SimpsonAngus). (the more usual low dose buspirone use is summarized in Table 3B)

Table 3B Low-dose buspirone treatment is approved for anxiety.

a. Low dose Buspirone acts as a serotonin 1A partial agonist: About $15 \mathrm{mg}-60 \mathrm{mg}$ per day ${ }^{17,28}$

b. Significant serotonin neuromodulator because serotonin $1 \mathrm{~A}$ acts on the presynaptic receptor at $5-15 \mathrm{mg} /$ day as a full agonist ${ }^{17,28}$

c. At $30 \mathrm{mg}-60 \mathrm{mg} / \mathrm{day}$ it is post-synaptic serotonin 1A partial agonist (critical) $)^{17,28}$

d. Drug is usually marketed for anxiety: Anxioselectivity in doses of $15 \mathrm{mg}-60 \mathrm{mg}$ /day as the most selective serotonin $1 \mathrm{~A}$ partial agonist post-synaptically; presynaptically as full agonist ${ }^{17,28}$

(may be useful as adjunct in attention deficit disorder and in

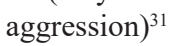

The TD patients I have seen have almost always been referrals with already pre-existing movement disorders referred by psychiatry, neurology, gastro-enterology or primary care. They have been treated with full awareness that the treatment is out-of-labeling. Though the numbers are substantial during this quarter century (1990 to 2015), I don't have the exact numbers of patients I've treated for tardive dyskinesia with high-dose buspirone. But, as I recall, surprisingly perhaps, all $100 \%$ of patients I've treated with documented TD, have improved dramatically. I have never had to discontinue the buspirone and have not seen any significant safety issues. The only issues appear to have been nausea in a few, and diarrhea in that first patient reported in the Lancet. I did not ever encounter any psychiatric compromise of the patients' conditions, and, at times have seen some improvements in their psychopathology. However, I have never seen buspirone exhibiting antipsychotic effects, though many patients with histories of psychosis have reported greater ease in dealing with stress, anxiety, irritability, depression and/ or agitation. They were invariably still on an antipsychotic, sometimes different, sometimes the same, and sometimes in lower dosage.

When the tardive dyskinesia was mild to begin with, the TD cleared. When it was profound, the improvement has been profound, in general, with most patients completely cleared after stabilization on medication, and all significantly better. Surprisingly, I cannot recall a single patient who did not tolerate the very slow build up to high-dose buspirone (at $120 \mathrm{mg} /$ day), but then I've been very careful, accommodating and encouraging in the doctor-patient relationship. But that is still remarkable. As I understand it, my limited number of colleagues who have been using this treatment and reported their results to me, have not indicated any failures for managing the dyskinesia. But these colleagues have consistently reported improvements to me of the TD, but these range from mild to profound. I have wondered whether that limitation of response has been insufficient because the dose might not have been increased enough after the clinicians were satisfied because they had noted some improvement. But they might not have targeted possible complete remission of TD signs and symptoms. They usually were not using measures like the STRAW where they could know the TD movements were still demonstrable and needed higher dosage; usage of tests like the AIMS, in my opinion is not as sensitive as severity and frequency are both not measured and the range of variation (e.g. 0 to 4 vs 0 to 100 when multiplying the two parameters) is less sensitive. And I cannot also guarantee that they have only reported improvements, and those that have not, have not contacted me, so this is a potentially positively skewed sample of reports and negative in terms of optimal results. Importantly, colleagues infrequently diagnose TD when the patient does not have TD: Generally this misdiagnosis may be because the short-lived withdrawal dyskinesias on diminishing a neuroleptic dose occurred; alternatively the clinician might have labeled a normal variant for the patient: "Yes, for years, long before my medications were added, I have been moving my leg (... or my lips ... or my tongue) like that: It's my habit" Again, careful TD scoring examinations should lower that misdiagnosis. Alternatively, some colleagues are unsure of the movements and asking for a second opinion, and these diagnoses can rarely even include seizure phenomena or those "normal" or maybe ritualistic compulsive habits. Clearly, these might not respond to high dose buspirone.

The same improvement cannot be said for tardive dystonia. Some long-standing patients with severe tardive dyskinesia, had also developed prior muscular spasm reactions which were persistent (tardive dystonia). The dystonias do not appear to have responded to buspirone, except marginally, because some dyskinetic improvement may still secondarily slightly improve the spasms. I regard the mechanism of dystonia as different to the dyskinesia-it's not due to super sensitivity. But the dystonia also apparently might reflect a greater level of chronicity: Possibly the untreated dyskinesia has progressed so much that the patient has moved to a further muscular phase with maintained stiffness. I argue this point because I have never seen neuroleptic induced tardive dystonia without preceding tardive dyskinesia-the dystonia seems to only temporally follow the dyskinesia.

Finally, as I have suggested in this paper, when I have used buspirone with neuroleptics prior to any TD developing, and even though I monitor these patients generally at every appointment, I have not seen TD developing. However, TD is now rare given appropriate dosing of the carefully chosen medication for the correct condition. It is, however, very surprising that high dose buspirone has not been used more generally in tardive dyskinesia, perhaps because it is seldom mentioned in review articles. ${ }^{32}$ When it has, it is used in low doses (e.g. Goff used on average $23 \mathrm{mg} /$ day). ${ }^{33}$

Partial agonism is reflected in Table 3C.

Table 3C Partial agonists properties

A. Partial agonists

B. Differentiate partial agonists from inverse agonists and neutral agonists

C. Inverse agonists (IA) bind to the same receptor as an agonist. IA induces a pharmacological response opposite to that agonist (scoring e.g. -10/10). But an inverse agonist will not produce a normalization of super sensitivity. Acts the same way irrespective as an antagonist

D. Neutral antagonists (NA) have no activity in the absence of an agonist or inverse agonist but can block the activity of either. But a neutral antagonist will not produce a normalization of super sensitivity. It blocks, but does not reverse (scoring e.g. 0/10)

\section{E. Partial agonists (PA) have two properties:}

I. Bind to and activate a given receptor in the presence of no agonist but with only partial efficacy at the receptor relative to a full agonist (scoring e.g. 5/10) 
II. Partial agonists partly block the antagonism (like incomplete inverse agonist?) in the presence of the antagonist so result in 5/10: This normalizes. Only partial agonists can produce this normalization.

a. In the presence of a full agonist, partial agonists show functional antagonist activity, as receptor binding reduces the response from that seen with the full agonist.

b. In the presence of super sensitivity of the receptor, a partial agonist will subsensitize appropriately effectively normalizing.

In Table 3D, partial agonism is summarized for buspirone.

Table 3D Partial agonists and buspirone

a. Buspirone is a serotonin 1A partial agonist (in regular doses)

b. And dopamine (2) partial agonist (in high doses) acting on dopamine receptors.

c. This should start in TD patients at about $120 \mathrm{mg}$ per day in our experience

d. In the presence of super sensitivity of the receptor, a partial agonist will sub sensitize appropriately

e. Effectively, this produces a normalization of super sensitivity.

I maintain the assumptions that there is no successful treatment for TD are incorrect: In this instance, I hope to assist practitioners and might help patients as it appears that high-dose buspirone might be a strong option for management. I'm saying "might" though I am convinced of its success; "might" here is to be conservative and until a large body of evidence is acquired as to efficacy and safety issues, though in our experience high-dose buspirone when appropriately prescribed for TD appears safe and successful. However, there are no other persuasive treatments.

i. Because it is seldom mentioned that there are adequate treatments for TD, the condition is often regarded as being incurable, when I maintain that it is not. Drugs such as tetrabenazine ${ }^{34-41}$ and reserpine ${ }^{42-47}$ may be most frequently mentioned, with closapine being the classical neuroleptic to use in cases of TD if a neuroleptic were necessary.

ii. Clozapine, an atypical neuroleptic, does not cause extrapyramidal symptoms of Parkinsonism and dystonia and appears to have a reduced or absent capacity ${ }^{48-55}$ to produce tardive dyskinesia. ${ }^{49}$

iii. But the balance of response, side-effects and sometimes costs does not make the treatments encouraging. This is why I am emphasizing high dose buspirone.

iv. All the comments I have made about careful prescription of outof-labeling medications should be taken into account and there should be consultations with specialists from the appropriate medical background. Prescription is linked with regular monitoring and adaptation of dose. ${ }^{56}$

v. Neuroleptics are dopamine receptor blocking agents and are often classified as either

vi. Antipsychotic agents: These are generally used for psychosis and its prophylaxis, including schizophrenia, bipolarity, schizoaffective and autistic disorder. Latterly, some, for example the "atypical second generation antipsychotic drugs" such as aripiprazole, have been used as adjunct in depression and anxiety. Haloperidol was a commonly used example of the classical "first generation antipsychotics" that particularly created a risk for TD; or vii. as medications for gastro-esophageal conditions such as reflux or nausea, for example metoclopramide and prochlorperazine. Metoclopramide involves the so-called circum ventricular organs in its passage through the brain and appears specific for the dopamine D2 or D2 /D3 systems. ${ }^{57,58}$ As pointed out in this paper, this dopaminergic selectivity may increase the TD risk.

Drugs that affect dopamine affect the basal ganglia as dopamine nuclei and structures are linked up with the BG. Consequently, several medical conditions, commonly Idiopathic Parkinson's disease manifest this way due to their BG pathology, as does another frequent condition Restless Legs Syndrome. Of course, some dopamine excess may be linked with psychosis. Our neuroleptic medications block dopamine and therefore can produce side-effects of dopamine deficiency such as drug-induced conditions. This is simplistic as we have many neurotransmitters and most medications are not specific just for dopamine: Some like sulpiride and pimozide, both seldom used, are. ${ }^{17,28}$

I have been told that there are those who disclaim such ideas on the Internet but I have never encountered a reported failed real case with appropriate monitoring and dosing. I speculate as to the reasons for these reports of possible failures:

i. anecdotal undocumented reports:

ii. not having done the research;

iii. not understanding the difference between neuroleptic withdrawal dyskinesia (a short-term phenomenon when going off neuroleptics) where the dyskinetic movements are not maintained and quite reversible, and yet misinterpreting this as Tardive Dyskinesia, to which it is not related.

iv. not having built the dose sufficiently;

v. not having monitored the responses.

Clearly, we must appropriately diagnose every pharmacological intervention including withdrawal from neuroleptics and other changes. The expectation is that if patients are withdrawn from neuroleptics they might have "withdrawal dyskinesias" which we should distinguish from tardive dyskinesia and this may occur irrespective of their other medication.

\section{Part 4: Clinical summary}

The bottom line is the following:

Since my original publication in the Lancet in December 1989, I have never encountered a single reported failure on high-dose buspirone treatment in tardive dyskinesia (TD) by clinicians using this compound in the appropriate recommended manner: This would include slow build up, careful proper monitoring, seeing the patient frequently in follow up, spacing the buspirone out over the day, and adjusting the dose based on response.

So far, there has always been some positive response provided the dose is adequate and usually the response results in almost complete resolution of the movements. This is not surprising and, indeed, predictable because the mechanism is such that buspirone, in high doses only, is a dopamine partial agonist which means that in the presence of dopamine super sensitivity it will normalize the receptor.

\section{Part 5: Dosing}

Treatment with buspirone requires careful handling, patience, regular-sometimes weekly-appointments until stability of dose is achieved, and patient education about the effects of this drug. 
Remarkably, these TD patients, in general, tolerate the buspirone dose well and, in our experience, have far fewer side-effects than patients treated with buspirone for anxiety. For example, we seldom see what Neppe has called the key serotonin 1A side-effect of Non-vertiginous Dizziness -the strange "dizziness" shortly after taking buspirone and lasting half an hour. However, the advent of many different buspirone generics has made management of dosing more difficult, and once a patient is established on a specific generic, they should stay on that dose.

In general, the lowest suitable dose that can begin to show differences is $120 \mathrm{mg}$ total per day usually in at least 3 divided doses per day with meals, sometimes 4 or 5 or even 6 adjusted doses. The meals help avoid any nausea-now more common with generics. At that point, in some, one may see slight changes, yet with others they may be significant. If the patient is still symptomatic, with only a slight response, higher doses are gradually used. This is sometimes an error of accepting the slight improvement when just pushing the dose to the limit can result in much more TD control. This way even severe or profound dyskinesias become much improved.

When we have used this, patients have been monitored very carefully for change with a formal evaluation: usually I use the STRAW evaluation as in my experience the most sensitive TD evaluation but I also score patients with several others (as below) as well. The highest dose I have personally used has totaled $330 \mathrm{mg}$ per day usually taken in five divided doses. It's important to know how to use high-dose buspirone. I start low, e.g., $7.5 \mathrm{mg}$ bid and build slowly over several weeks, by $7.5 \mathrm{mg} /$ day in the TD population every second day or so monitoring carefully (in e.g., anxiety I build every fourth day). I have not seen significant adverse effects at this dose. These patients tolerate the buspirone well. The most common minor side-effects appear to be nausea. When this is reported, changing the time of dosing, such as taking the buspirone with meals, usually solves this. It may also be necessary to change the generic version, as generic substitutions are not pharmacologically exactly equivalent. This might mean careful review a week or two later, with slight adjustments of the dose based on the responses to the newer generic

Part 6: Is clinical experience meaningful in today's double-blind world? ${ }^{\mathrm{e}}$

The dilemma: ${ }^{59,60}$

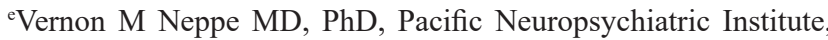
Seattle, WA

i. Do you write about something that is not approved by the FDA?

ii. Do you mention a study that is single blind, not double blind, when there is no double-blind study on that drug?

iii. Particularly, do you emphasize that the single blind study was deliberately performed because the data appeared so strong that you regarded a double blind study as possibly not even ethical?

iv. Do you mention a treatment where the continued combined experience of a quarter century shows it appears to be the most successful and safest treatment for a previously incurable condition?

v. And do you discuss that same treatment which somehow the literature has glossed over?

I would hope most scientists and clinicians would answer the above questions, "Yes, I would discuss these: It would be inappropriate not to". Yet many publications would reject such concepts, requiring purely controlled double- blind versus placebo studies.
Consequently, we might be poorer as physicians because we cannot benefit from real experience, substantial knowledge and clinical know-how. Double-blind studies have their merits, but must not be overvalued. Often a marginal difference in efficacy of the active drug versus placebo (e.g., say $55 \%$ vs $40 \%$ ) does not lead to appropriate use in the real patient where, almost every time, we would want to see the great majority responding with limited sideeffects. Ironically, the low percent success in some double-blind studies can translate to a much higher success in real patients, but this is not always the case. That difference is because in clinical practice, the astute physician prescribes the drug carefully, in the proper dose for the correct duration, and at the appropriate dosing frequency schedule through the day (e.g. five times a day if needed). By these means success should be more likely. This individualization optimally utilizes all special and personal factors in that particular patient, including the presence of other medications with their pharmacokinetic and pharmacodynamic interaction, psychosocial issues, as well as compliance issues, plus even pharmacogenomics, when available. A competent and experienced consultant can evaluate such clinical differences. ${ }^{56}$

In double-blind research neither the patient nor the physician knows whether the drug under study in that patient is placebo or active drug. They certainly don't know what the dose being administered is (if there is more than one dose of active drug). In these double blind studies, the dose and frequency may be incorrect for that patient, as individual treatment is important. Ironically, such a study may produce a situation where there is an error: Drugs that are efficacious may not be interpreted as such. This is because in the double-blind study, the wrong dose might be used for the specific patient under consideration, and the patient will fail, whereas at an appropriate dose and frequency of administration, the patient might have responded. ${ }^{59,60}$

Table 3.6E: Blind studies

A. Double blind studies: Problems

a. Valuable and standard but imperfect

b. Problematic

c. Statistical not clinical

d. Dosage unknown

e. Ethical problems

$=$ This applies to high-dose buspirone where we did a single blind study.

\section{B. Single blind buspirone justification}

a. Replicated our original clinical impressions at Washington University, St Louis. ${ }^{21}$

b. Single blind because at that stage a double blind study would not have been ethical.

c. Dosage was known

d. Patients did not know the dose and that they were receiving any active agent.

e. Replication of the Neppe clinical reports

\section{Part 7: Understanding HDB in TD.}

In clinical use, the patient and physician can combine to apply these rules appropriately. And unlike publications, this is a timehonored method. This is the way Medical Students have been taught 
by Attending Specialists for years. They share their clinical skills and yet there is a bizarre paradox where expectations are different for published material. There is a place for clinicians to share their experience. $^{56}$

Specifically, it might be particularly valuable to draw to the attention of my colleagues a treatment that many have struggled to assess and treat. The topic in this discussion, tardive dyskinesia (TD) is often an area of neglect in clinical practice and in education of colleagues and students, and it should not be disregarded as it is too important. There are no approved medications for tardive dyskinesia. Other than high dose buspirone treatment, there are no drugs that have been demonstrated to have anything but a marginal effect on the condition. Therefore, this paper emphasizes what has become a standard management, in my experience.

But we require justification of why it works, hence the mechanisms, dosing, safety and animal experience is pertinent. But it requires a way to assess management and that means a standardized method of evaluation, hence the STRAW test for measuring change is discussed.

This paper is not meant to be a comprehensive review of the literature on this topic. Instead, it is targeted towards a clinical priority perspective, where areas that I deem pertinent are emphasized.

\section{Part 8: Buspirone in high doses provisionally appears safe ${ }^{\mathrm{f}}$}

fVernon M Neppe MD, PhD, Pacific Neuropsychiatric Institute, Seattle, WA

I discuss in detail the neuro pharmacology of buspirone in an older book Innovative Psycho pharmacotherapy. ${ }^{17}$ The treatment appears to be very safe. I have not encountered significant adverse side-effects, or need to withdraw the buspirone when treating the tardive dyskinesia. I've been surprised at how well the buspirone is tolerated in the TD population, almost as if teleologically the patient needs it receptorwise. This is in contrast to other populations where a small proportion require discontinuation (particularly now with the multitude of generics on the market) when used for e.g., anxiety (indication) or outside labeling in agitation, irritability or allowing SSRIs to continue working or as adjunct in combinations (and with these invariably within labeling because anxiety is so protean in these populations). Still the most common side-effect may be nausea when the drug is not taken with food, and the only time I saw diarrhea was in the first case I reported when it was postulated to be serotonin linked and I gave nadolol as a serotonin 1A blocker (an effect that I clinically deduced) which relieved it immediately.

There was already data using buspirone in doses of $1200 \mathrm{mg}$ day and more in pre-approval research relating to using the drug in schizophrenia: It did not work for the treatment of that condition, but apparently the management was safe. In those early studies in schizophrenia, buspirone was well tolerated but it did not have any antipsychotic effect clinically and did not exhibit the "typical neuroleptic" profiles in rodents, namely cataleptic features. I point this out to illustrate that we are usually used to doses of $15 \mathrm{mg}$ $60 \mathrm{mg}$ buspirone per day, for the usual indication of anxiety, or for the pharmacological equivalent of this, namely regulating serotonin due to buspirone's specific serotonin 1A partial agonist effects. However, in that anxiety population the buildup is slow and individualized due to the side-effect of what I've called "non-vertiginous" dizziness (NVD). ${ }^{17}$ In my experience, the medication is better tolerated in TD patients and we seldom see NVD, ${ }^{27}$ though the various generic buspirone preparations have become a major confounding issue. ${ }^{61,62}$ That is why a change of generic results in the consequent need for dose re-calibration, because there may not be dose equivalence any longer: At the extremes, a $100 \mathrm{mg}$ dose of a drug could deliver, say, $80 \mathrm{mg}$ on one generic, and $125 \mathrm{mg}$ on another using the FDA's acceptance of equivalence (the $80 / 125$ rule). ${ }^{17,28,61,62}$ In tardive dyskinesia management the dose adjustments are critical and patients' TD movements can easily become poorly controlled.

\section{Part 9: Clinical dilemmas using high-dose buspirone in TD}

When to increase the dose: If the patient's TD remains symptomatic, even if improved, I go higher. I target seeing complete remission. I know I can always decrease the dose which sometimes I do later, not so much because of side-effects, but because circumstances like stressors have changed.

Building up slowly versus quickly: I've always titrated slowly so don't know what would happen if the dose was built up in a few days. It may take three weeks to get to $120 \mathrm{mg} /$ day and that results in a fascinating component. Sometimes we see nothing until it hits $120 \mathrm{mg} /$ day. Now if we go quicker, it may work earlier, but I have no experience with that regimen.

Toleration of the HDB: Remarkably, in the past, lack of toleration was almost never an issue when the branded Buspar was being used for tardive dyskinesia. This lack of toleration is still uncommon but it depends on the generic. I carefully check what the generic is, and want to ensure that is consistent. As a last resort, I change the generic.

The highest dose to use: The highest HDB dose we've used was $330 \mathrm{mg}$ daily. He was one of the most severe TD cases I've seen. We have video evidence. The patient took the $330 \mathrm{mg} /$ day dose during a phase when the $240 \mathrm{mg} /$ day was suddenly insufficient. He had not changed generic, but was under more stress, a not uncommon situation for him. Stress always aggravates. We pushed up the dose gradually, but his movements were still not fully controlled. This $330 \mathrm{mg} /$ day patient was under excellent control, such that only his dystonias manifested, until he went onto a preparation with high doses of Vitamin B6. Suddenly his movements were much worse. That was the first time I had seen that. Recognizing this happens sometimes with Sinemet and B6 in Parkinsonism, I stopped the B6 and within days he was back to baseline. We were then able to taper his dose back slightly to $300 \mathrm{mg}$ per day, as there had been other adjustments of this necessary neuroleptic (closapine).

Collaboration with the USA pharmacies: I will write on the prescription that this is for TD. Sometimes I even provide citations. In the early days, I had some queries. Now I don't have problems, but sometimes I initially need to speak to pharmacists personally to explain to them. Once the patients are on this, with them having seen what they were like before, they're amazed. I never cease to be amazed either. The impact is so profound.

Collaboration with the USA insurances: I've never had a problem with patient's insurances provided we explain to them the reasoning and give them literature. Essentially, the morbidity and costs of TD appear considerably less with this treatment.

Using neuroleptic as well with the high-dose buspirone? In many but not all cases, the patient has still required some dose of neuroleptic for their underlying condition. Usually the dose was lowered considerably, but very slowly over time, and with careful monitoring because, inter alia, there is sometimes a withdrawal dyskinesia syndrome, and even those without TD may so manifest, and TD patients may temporarily get worse.

Differential responses with increased doses: We typically see a stepwise lessening of the TD as we push the dose. Yes, in my experience, 
always. This is very much dose dependent. We see early clues at about $120 \mathrm{mg}$ per day, occasionally earlier even $90 \mathrm{mg} /$ day and stepwise diminution. Many patients with mild TD to begin with may just require $120 \mathrm{mg} /$ day.

Possible use of buspirone as prophylaxis against TD when prescribing neuroleptic: The jury is not yet in. Even though I monitor these patients generally at every appointment, I have not seen TD developing, if clinically indicated I sometimes use buspirone with neuroleptics prior to any TD developing. Effectively, I have never in 25years seen a case of TD with a patient on neuroleptics plus buspirone taken for about as long a period as the neuroleptics. The buspirone dose here is generally at the anxioselective dose range (e.g., $30 \mathrm{mg}$ bid) and that puzzles me a little (certainly in TD management, buspirone almost invariably requires doses of $120 \mathrm{mg}$ /day or higher to be efficacious). If there is a pharmacodynamic mechanism, it would be via the previously mentioned Serotonin 1A partial agonism which indirectly might impact the dopamine receptors (we know this because of an animal model ${ }^{63}$ and clinical application). But I'm speculating about whether the buspirone is working pharmacodynamically in TD prophylaxis. However, TD is now a rare condition given appropriate dosing of the carefully chosen medication for the correct condition so its non-occurrence in TD may not prove anything.

Moreover, we have to look at all drug interactions, pharmacokinetic and pharmacodynamic. This raises many questions particularly as many of the neuroleptics are metabolized through the 2D6 portion of the P450 cytochrome enzyme system and it's very common for patients to be either intermediate metabolizers or poor metabolizers.

\section{Part 10: Buspirone and drug interactions ${ }^{64,17,65}$}

Buspirone is metabolized predominantly through the $\mathrm{P} 450$ $3 \mathrm{~A} / 34$ system. Buspirone is well absorbed, but is subject to firstpass metabolism. It produces several hydroxylated metabolites, including the essentially inactive 5-hydroxy-buspirone and 1-pyrimidinylpiperazine (I PP) The 1PP metabolite is about 10 percent as potent as buspirone in a variety of pharmacologic tests. The half life varies widely from 2 to 33 hours. Buspirone is highly protein bound (more than 95 percent), interacting with both albumin and alpha-acid glycoprotein. It is predominantly metabolized through the liver, but renal disease produces a modest decrease in buspirone clearance.

\section{Part 11: Other treatment options to manage tardive dyskinesia}

i. All TD medication is out of labeling so all treatments are innovative.

ii. All treatments have been unsuccessful or irregularly or occasionally or minimally successful

iii. The one major exception has been high dose buspirone where I have yet to see or hear of a failure provided the required dose (e.g. $\geq 120 \mathrm{mg} /$ day) is reached. But sadly it's been less used than it should be.

The condition, in this instance, is tardive dyskinesia (TD) and the data below has been substantiated such that discussion is appropriate. Clarifying that data allows neurologists, psychiatrists, neuropsychiatrists, and movement disorder specialists choices as to what to prescribe and how to assess these patients. This is particularly so in this instance because prior publications on other treatments are apparently substantially inferior, ostensibly more dangerous, and often more expensive. The main ones involved for tardive dyskinesia treatment are on dopamine depleting agents like tetrabenazine $\mathrm{e}^{34-41,45-47,66,67}$ or broader depleter like reserpine $\mathrm{e}^{68-70}$ or alpha methyl dopa ${ }^{68-70}$ Alternatively we see even benzodiazepines ${ }^{39,71-73}$ or Vitamin $\mathrm{E}^{39,74-98}$ or anticonvulsants ${ }^{99,100}$ as alternative experimental clinical attempts to treat TD. Other techniques involve changes round from one neuroleptic to another. There appear to be so many options because none of these treatments have been unequivocally successful. ${ }^{34-41,68-70,74-98,101-124}$

Table 3.11F: Most commonly written options for managing tardive dyskinesia.

These are useful theoretically but in practice have not produced any consistent, demonstrable effects. The reason using the Dopamine supersensitivity hypothesis: The treatment requires receptor subsensitization and only Dopamine partial agonists do that (plus at least impacts of Dopamine 1 and 2: Only HDP does that ${ }^{1,21}$.

A. Try depleting dopamine. Dopamine depletion:

a. Reserpine ${ }^{43,68,69}$

b. Tetrabenazine ${ }^{34-38,40,41}$ Kazamatzuri; study in 1973 produced poor results with $25 \mathrm{mg}$ daily ${ }^{35}$.

c. Alpha methyl dopa ${ }^{68-70}$

B. Try stimulating dopamine: Dopamine agonists:

a. Bromocriptine $e^{125-127}$

b. Amantadine 1982. ${ }^{128-132}$

c. Levodopa e.g. 1982 Casey's work $^{133}$

C. Vary the dopamine levels

a. Drug Holidays 1980 The Belmaker team found this dis not work. ${ }^{134}$

b. Long-term depot neuroleptic claims of protection have been made. But most say this is "worse"

c. (may be epidemiological). ${ }^{135-138}$

\section{Try Supplements:}

a. Lecithin 1979 e.g. Jackson $50 \mathrm{~g}$ vs placebo ${ }^{139}$ crossover over a short while ${ }^{139-145}$

b. Vitamin $\mathrm{E}$ is commonly used but without difference. ${ }^{91-95,97,98}$ Note this may be simplistic: There are various kinds of Vitamin E.

c. Vitamin B6 is proposed ${ }^{146,147}$ but in our experience might sometimes worsen.

E. Common options tried and theoretically important.

a. Maybe one neuroleptic is okay. Closapine which has D1 and D2 and is balanced by Serotonin effects may be the best option. $^{148-151}$

b. Different neuroleptics D2 partial agonists (Aripiprazole, Brexpiprazole) This idea may be correct, but needs to have D1 involvement too to maximize. Aripiprazole doesn't. (Buspirone acts on D1, D2, D3, D4) ${ }^{152-156}$

F. Common option which helps diagnosis because it worsens the TD.

a. Anticholinergics were tried to improve TD, but then makes it worse. ${ }^{157}$

G. Other neurotransmitters 


\section{GABA $^{73,158,159}$ Propranolol 1980 Wilbur}

Morphine, naloxone, enkephalin ${ }^{160,161,162} 1980$ Bjorndal No!

Verapamil $^{163}$ and Calcium blockers ${ }^{164}$

These are summarized in Table $3.11 \mathrm{~F}$

In this instance, I use as an example high dose buspirone therapy in tardive dyskinesia. ${ }^{g}$ I do this not only to make the valuable point that clinical experience should not be ignored, but because this treatment allows understanding of a valuable treatment option for clinicians. There is no approved drug for TD, so that automatically makes any treatment for this condition out-of-labeling. But, importantly, there is a literature on managing tardive dyskinesia with high-dose buspirone with which I can justify its use. As with every pharmacological intervention, care, monitoring and treating the whole patient are always necessary.

${ }^{g}$ Busprone is the chemical generic name for the branded drug, Buspar. Buspar has been generically substituted for many years.

\section{The proposed mechanism of tardive} dyskinesia: supersensitivity: section $4 .^{\mathrm{h}}$

${ }^{\text {h }}$ Vernon M Neppe MD, PhD, Pacific Neuropsychiatric Institute, Seattle, WA

\begin{abstract}
This fourth significant issue provides an important, major theoretical demonstration of the mechanism of tardive dyskinesia, namely the proposed mechanism of tardive dyskinesia. The dopamine 2 or 2-3 supersensitivity hypothesis as a cause of TD is strongly supported by HDB. This significant issue provides an important, major theoretical demonstration of the mechanism of tardive dyskinesia, namely the proposed mechanism of tardive dyskinesia. The dopamine 2 or 2-3 supersensitivity hypothesis as a cause of TD is strongly supported by HDB. It appears the most likely major factor impacting on TD as buspirone is the only marketed pure dopamine partial agonist acting at the dopamine 2/ 3 (and also dopamine 1) levels. Therefore, high-dose buspirone should subsensitize supersensitive dopamine receptors if the supersensitivity hypothesis is correct and improve tardive dyskinesia, and it does so. Moreover, lower doses of buspirone should not achieve an improvement effect on TD and do not. This is because buspirone in doses such as $30 \mathrm{mg}$ to $60 \mathrm{mg}$ per day it is a serotonin $1 \mathrm{~A}$ partial agonist and does not act appreciably on dopamine.
\end{abstract}

In 1990, I postulated that high dose buspirone would work in almost every case of tardive dyskinesia because:

i. In the presence of supersensitivity of a receptor, a partial agonist subsensitizes that receptor, effectively reversing that supersensitivity.

ii. Effectively, I have supported this hypothesis with our empirical data.

I have postulated the following mechanism:

i. Tardive dyskinesia is the classical supersensitivity state at the dopamine receptor, so a partial agonist at the dopamine receptor level would be expected to work well. In the presence of partial agonists, a supersensitized receptor will become subsensitize.

ii. The only azapirone compound is buspirone, and this group might all have a dopamine partial agonist effect in high doses. So technically, other experimental drugs could work but this would need proving. The TD equivalent doses for buspirone at the dopamine level is above about the $120 \mathrm{mg}$ daily limit given in appropriate divided doses - in mild TD usually $40 \mathrm{mg}^{\mathrm{i}}$ thrice daily is sufficient. Again, buspirone works in tardive dyskinesia because TD is the classic dopamine supersensitivity state, but only at those kinds of high doses.

${ }^{i}$ Buspirone is one of the few medications that can be split into two or three. The most easily available size is $15 \mathrm{mg}$ though some pharmacies stock the more convenient $30 \mathrm{mg}$ size.

iii. In more usual lower doses, buspirone is very selectively a partial agonist at the serotonin $1 \mathrm{~A}$ level, and does not usually impact the dopamine receptors.

\section{Mechanistic amplification}

Let's amplify a little: The detailed neuropharmacology of buspirone had allowed me to postulate its logical theoretical mechanism in tardive dyskinesia:

My early buspirone education led me to an awareness of a rather bizarre dichotomy:

i. The drug buspirone in very high doses $(600 \mathrm{mg}$ to $1000 \mathrm{mg}$ per day in humans) appeared to have a dopamine-related action.

ii. Buspirone had a mild agonist effect on the dopamine receptors in these high doses in the presence of dopamine antagonists. However, without dopamine antagonists, it had a mild dopamineblockade effect. When I treated my first patient I saw the mechanism initially as similar to intrinsic sympathomimetic activity in beta-adrenergic agents.

iii. But in 1990, I described what I was seeing as dopamine partial agonism and it was the only drug, at that time, known to have this effect. ${ }^{17}$

My major rationale for using high dose buspirone in tardive dyskinesia (TD) ${ }^{1,21}$ was therefore very much a pharmacodynamic phenomenon. I knew, too, that in much lower doses, such as $30-60 \mathrm{mg}$ per day, buspirone was a serotonin $1 \mathrm{~A}$ partial agonist. In order to treat TD, I hypothesized that both the serotonin $1 \mathrm{~A}$ and dopamine receptors would be involved. Because dopamine super sensitivity in TD was occurring, thus in the presence of super sensitivity of the dopamine receptor, the dopamine partial agonist buspirone (at high doses) subsensitizes that receptor, effectively reversing that super sensitivity. Buspirone theoretically had to work because tardive dyskinesia is the classical dopamine super sensitivity state, and therefore, theoretically, a dopamine partial agonist should treat the condition and maintain the results. And it appears to do exactly that in clinical practice. I knew about the safety studies, nevertheless I postulated we would not need doses of (say) $600 \mathrm{mg}$ a day. But I knew such doses had been proven to be safe in the experimental literature on buspirone.

Imagine the excitement in that first case where the patient suddenly and dramatically started to improve at about $110 \mathrm{mg}$ or $120 \mathrm{mg}$ per day with no effects before that. We had to wait for buspirone to show its dopamine partial agonist effect in high doses (about 120mg daily or higher in divided doses): In more usual lower doses, buspirone as a very selective partial agonist at the serotonin 1A level, should not usually impact the dopamine receptors. We know that based on animal pharmacology. Buspirone apparently works because at high doses it has a dopamine partial agonist effect, and in the presence of super sensitivity of a receptor it will subsensitize this. ${ }^{165,166}$ In tardive dyskinesia the proposed mechanism is dopamine receptor super sensitivity. ${ }^{11,16,19,59}$ There is also a role of the serotonin partial agonist effect. ${ }^{167-169}$ The fact that buspirone works in almost every case of 
tardive dyskinesia, suggests the proposed mechanism of TD is correct as proposed.

I also postulated that differential dopamine 1 and 2 effects were critically important in TD. Dopamine is often abbreviated DA. DA 2 selective drugs would cause more TD than DA 1 and DA 2 selective agents. Today, we know that there is a dopamine-2 family including DA-3 and DA-4, and that DA-5 may be part of the DA-1 family. Genes have been cloned but the differentiation of DA-2 from DA-3 is still somewhat unclear and we sometimes refer to DA 2/3. It is this group of selective neuroleptics such as haloperidol that might increase the TD risk. Our work and my original hypothesis in 1989 has implied that TD was due to DA 2 (or now DA 2/3) supersensitivity. ${ }^{17}$ This postulation has now been justified. Similarly, and even more so, the subsequent experience in humans and animals, have supported the supersensitivity hypothesis of DA for TD.

\section{Support for the DA 2/3 supersensitivity hypothesis}

Jeste and Wyatt argued that tardive dyskinesia may or may not be due to postsynaptic dopamine (DA) receptor supersensitivity. ${ }^{170}$ Yet, this most popular theory of the pathophysiology of neurolepticinduced tardive dyskinesia (TD), which attributed the movement disorder to central postsynaptic dopamine receptor supersensitivity, was regarded as based on circumstantial evidence:

a. Central catecholaminergic overactivity is present in TD and it could result from presynaptic and/or postsynaptic disturbances.

b. Postsynaptic dopamine receptor supersensitivity is a normal consequence of neuroleptic administration and is not sufficient to explain why TD develops only in a proportion of patients receiving long-term neuroleptic treatment. Postsynaptic dopaminergic supersensitivity may be responsible for withdrawal dyskinesias, but clinical studies do not support the supersensitivity hypothesis in most patients with persistent TD.

c. Noradrenergic hyperactivity and presynaptic dopaminergic overactivity may be necessary for the induction of at least certain subtypes of TD.

It seemed in 1989 and the early 1990s, that there must have been a greater requirement to favor the supersensitivity hypothesis linked with TD. In a way, Neppe's high-dose buspirone data strongly supported that normalizing supersensitive receptors would improve TD. ${ }^{63}$ In medical parlance this creates a strong bidirectional causal correlation..$^{60,171-173}$ Importantly, the Neppe human work is supported by an animal model of tardive dyskinesia. ${ }^{63}$ Behavioral parameters of orofacial dyskinesia were quantified in rats. Chronic buspirone treatment was able to increase apomorphine-induced yawning behavior, suggesting that buspirone attenuates reserpineinduced orofacial dyskinesia through the development of dopamine autoreceptor super sensitivity. ${ }^{63}$

a. Antagonism of dopamine supersensitivity by estrogen in neurochemical studies in an animal model of tardive dyskinesia shows that exogenous estrogens may modulate the number of dopamine receptors in the central nervous system and, as such, may decrease the incidence and/or relieve the symptoms of tardive dyskinesia. ${ }^{174}$

b. Neuroleptic drugs alter the dopamine transporter-mediated uptake and release of dopamine. This supports a possible mechanism for drug-induced tardive dyskinesia. ${ }^{175}$ The results imply that neuroleptic drugs would cause an overflow of DA in the synaptic cleft of extrapyramidal dopaminergic neurons, which could be one of the possible mechanisms of tardive dyskinesia. ${ }^{175}$ c. Supporting supersensitivity and its attenuation but other than buspirone, the authors showed that TD in humans is reduced in patients also taking anticonvulsant drugs, primarily carbamazepine (CBZ) and tested for a causal role of CBZ of this effect in rats. They argue that by reducing DA supersensitivity, CBZ may be useful in treating TD and other hyper dopaminergic states. ${ }^{100}$

d. Abnormalities in various neurotransmitter systems have been implicated in the pathophysiology of TD, including the dopaminergic, GABA-ergic, serotonergic, noradrenergic systems plus excitotoxicity of the glutamatergic system and oxidative stress. ${ }^{176}$ Three general types of animal models have contributed to our knowledge of TD and can be described as homologous, analogous and correlational models, but there are no empirically validated guidelines to follow when choosing a suppressive agent. ${ }^{176}$

e. Human dopamine receptor D2/D3 availability predicts amygdala reactivity to unpleasant stimuli. Thus, individuals with high prefrontal D2/3 dopamine receptor availability may be more responsive toward aversive and stressful information. Through this mechanism, dopaminergic neurotransmission might influence vulnerability for affective and anxiety disorders. ${ }^{177}$ This may be pertinent in TD.

f. There are genetic polymorphisms in the dopamine-2 receptor (DRD2), dopamine-3 receptor (DRD3), and dopamine transporter (SLC6A3) genes in schizophrenia. This is relevant for understanding the complexity of these receptors. ${ }^{178}$ The D3 dopamine receptor is important in neurobiology and potential clinical relevance ${ }^{179}$

g. Using receptor autoradiography, Mahmoudi et al., ${ }^{180}$ measured striatal dopamine D1, D2, and D3 receptor levels. Their results suggested for the first time that up-regulated striatal D3 receptors correlated with TD in nonhuman primates, adding new insights to the dopamine receptor supersensitivity hypothesis. The D3 receptor could provide a novel target for drug intervention in human TD. ${ }^{180}$

Table 4A Dopamine receptor families ${ }^{181-191}$

Five subtypes of dopamine receptor have been cloned.

A. D1 like receptor family: the Gs protein is involved and adenylyl cyclase would be activated. The action of the enzyme causes the conversion of adenosine triphosphate to cyclic adenosine monophosphate (cAMP). The D1 and D5 receptors are closely related, and couple to Gs alpha and stimulate adenylyl cyclase activity.

B. D2 like receptor family: the receptor combining with the Gi protein and its activated alpha- subunit then inhibits adenylyl cyclase so that the concentration of cAMP is reduced. Its activated alpha- subunit then inhibits adenylyl cyclase so that the concentration of cAMP is reduced.

In contrast, the D2, D3 and D4 receptors couple to Gi alpha and inhibit the formation of cAMP

(There may be 2 others, too e.g. Dopamine 6 and 7 but that is disputed.)

Other proposed mechanisms: Issue 4.2

One unproven speculation is that altered sensory flow to motor systems results in this syndrome. Verification of such a mechanism 
could lead to early detection and improved treatment of tardive dyskinesia. ${ }^{192}$ An animal model for coexisting tardive dyskinesia and tardive parkinsonism involves a glutamate hypothesis for tardive dyskinesia. ${ }^{193}$ There is some support for this as an extra idea: There is evidence for long-term malfunctioning within five different brain GABA-ergic pathways in a monkey model for tardive dyskinesia (TD). Three of these gamma-aminobutyric acid (GABA) connections (technically called "GPe-STN, CP-SNr, and CP-Gpi") are chronically down-regulated during neuroleptic treatment, and after some years they do not seem to regain their normal activity, even when the neuroleptics are discontinued. ${ }^{193}$ Another two GABA malfunctioning connections were found in the monkey model: These pathways are up-regulated during chronic neuroleptic treatment partly due to an elevated glutamate release within the so-called "subthalamofugal" pathways. These researchers, Gunne \& Andren, ${ }^{193}$ hypothesize that TD may be due to an excitotoxic lesion of the inhibitory GABA-ergic afferents. ${ }^{193}$

I can add to this to explain that more than one researcher may be correct: They're not competing, just collaborating in a massive exploration. It's important to realize that dopamine 1 and 2 with its component, or additional, dopamine 3 receptors are not functioning in isolation. There is a musical symphony being played in the brain. Serotonin, norepinephrine, GABA and glutamate are some of the instruments co-ordinating this beautiful harmony. A GABA finding like this does not contradict another pertaining to dopamine supersensitivity. It simply adds to it. Although a substantial number of genetic studies have investigated TD, many of the positive findings have not been replicated or are inconsistent, which could be due to differences in study design, sample size, and/or subject ethnicity. We expect that more refined research will be performed in the future to resolve these issues, which will then enable the genetic prediction of $\mathrm{TD}$ and clinical application thereof. ${ }^{194}$ Anatomy is also controversial: Almost all studies have focused on basal ganglion areas. But in a whole-brain voxel-based morphometry (VBM) study, schizophrenia patients with TD had significantly reduced gray matter, mostly at the bilateral inferior frontal gyrus and the right superior frontal gyrus, which correlated with severity of clinical symptoms and involuntary movement, respectively. ${ }^{195}$

\section{Choice of neuroleptic: section $5 .^{j}$}

${ }^{j}$ Vernon M Neppe MD, PhD, Pacific Neuropsychiatric Institute, Seattle, WA

\section{Abstract}

The fifth issue is choice of medication for psychosis and related medical conditions. The choices relate to the (newer second generation) atypical neuroleptics (SGAs) compared with the older typical, first generation neuroleptics (FGAs). The generally more expensive SGA drugs have become far the major anti-psychotic agents in use in wealthy countries such as the United States, because of their efficacy and safety. A further preliminary theoretical postulate is put forward that the tardive dyskinesia effects are predominantly due to Dopamine 2 (or 3 as it is part of the same receptor family). If this were so, dopamine blocking drugs that are less selective (acting on dopamine 1 as well) should produce less risk of tardive dyskinesia than selective dopamine 2 (or 3 ) neuroleptic agents.

The issue here is choice of medication for psychosis and related medical conditions. There may be a differential predisposition to developing the condition. "Neuroleptic: is the term for dopamine blocking drugs.
These effects can be demonstrated in both the animal model and in clinical human practice. Neuroleptics are used predominantly in the management of psychosis, but are also used in gastro-enterology. Are there specific neuroleptics that may possibly be relevant for lowering the risk of TD?

First, it is well known that the (newer second generation) atypical neuroleptics (SGAs) are overall less TD inducing than the older typical, first generation neuroleptics (FGAs). This is postulated to be due to the predominant serotonin $2 \mathrm{~A}$ blocking effects. This is a major reason why the SGAs are preferred to the FGAs as this risk factor is lowered. However, the SGAs also appear to have more impact on the so-called negative symptoms of schizophrenia such as amotivation, apathy and withdrawal. ${ }^{196}$ Therefore the generally more expensive SGA drugs have become far the major anti-psychotic agents in use in wealthy countries such as the United States, because of their efficacy and safety (Table 5).

The lower the figure the greater the potency. https://en.wikipedia. org/wiki/Antipsychotic

$\mathrm{f}=\mathrm{HFC} \mathrm{h}=\mathrm{HC} \mathrm{r}=\mathrm{RC}$ V= very low but exact figures unavailable $\mathrm{M}=$ Midrange but exact figures unavailable

Overall, the results with the antipsychotic agents tested, support the concept that dopamine D4 receptor selectivity may confer clozapinelike antipsychotic efficacy and furthermore that dopamine D2 receptor selectivity may confer side effect liability (extrapyramidal side effects and tardive dyskinesia). ${ }^{181}$

\section{Use of neuroleptics in TD}

Optimally, we should discontinue the neuroleptic: For example in gastrointestinal disease as with metoclopramide. But often patients remain psychotic as buspirone is not an antipsychotic and the underlying prescription of neuroleptic was for antipsychotics. Then I individualize with the lowest possible dose of the most innocuous drug. This is one reason why atypical neuroleptics have been used, though there are still many TD reports with the atypicals. It may be that the other factor to differentiate is that the potent neuroleptics that acted on D1 and D2 receptors will be found to lower the risk. Interestingly, I have used the phenothiazine, perphenazine, in that regard, and have seen far less TD even though it is a "typical" neuroleptic, so that reevaluating beyond the current option of just looking at the newer atypical neuroleptics may rarely be valuable..$^{51,150,199-203}$

Importantly, choice of neuroleptic and early detection may be important as in the monkey model tardive dyskinesia can progress from reversible to irreversible. ${ }^{2}$

\section{Lower risk neuroleptics}

Given the literature and the epidemiological detail, I propose that D1 has an inhibitory motor effect on Dopamine 2 producing a balance that is important and may result in a lower incidence of tardive dyskinesia in neuroleptics which are D1 antagonists as well as D2 antagonists. The data suggests a much lower incidence of TD with the atypical neuroleptics. It will be interesting to observe how any atypicals separate out as less or more, as their still relatively minor pharmacological differences could ultimately express a significant difference. However, a prospective empirical epidemiological study would likely have to be enormous (possibly in the tens of thousands of patients) to generate significant results. This is partly because of many confounding factors such as the precise definitions of medications, diagnostic conditions, dose, severity, compliance, fluctuations, generic variations and assessment instruments. However, the major 
factor now is proper prescription of atypical neuroleptics should result only in a very low frequency of tardive dyskinesia.

Atypicals are unlike what we could observe in the past. In those times, the pre-atypical neuroleptic era, clearly the common compound that caused the most TD in clinical use was haloperidol, ${ }^{17,28}$ hypothetically because of its greater dopamine receptor specificity. This finding even apparently differentiated by country, where in the USA, Canada and Israel, TD was relatively profoundly clinically far higher, likely because haloperidol was the predominant neuroleptic. ${ }^{17,28}$ This compared with countries such as United Kingdom, South Africa, Australia and New Zealand, where, for example, the less dopamine selective phenothiazine compounds predominated. ${ }^{17,28}$ But now the differences between atypicals are far less striking than those between phenothiazines and butyrophenones.

\section{The newer atypical neuroleptics: Safety}

The newer atypical neuroleptics are safer than the FGAs, but not safe and likely they are different depending on profile such as dopamine specificity (higher for Dopamine 2 or $2 / 3$ selective drugs), and possible partial agonist effects (like aripiprazole).

The advent of these so-called "atypical neuroleptics", also called the "atypical antipsychotic drugs" or "second generation antipsychotics" (SGAs) heralded a new era in the management of psychosis. Prescribers, rightly or wrongly, largely abandoned the previous "typical antipsychotics" or the "first generation antipsychotics" (FGAs) such as the phenothiazines like perphenazine and chlorpromazine, and the butyrophenones like haloperidol. Instead, the advent of Clozapine (also called Closapine) heralded a new era of ostensibly safer drugs, where the risks of tardive dyskinesia were lower. Some of these drugs have received approval in various countries for use in different phases of schizophrenia, bipolar disorder, autism and atypical depression. The SGAs statistically are supposed to be safer in that there supposedly is a lower incidence of extrapyramidal side-effects such as Parkinsonism, akathisia and $\mathrm{TD}$, however, the data directly comparing specific SGAs with specific FGAs is very sparse. These SGAs had impacts not only on dopamine but also significantly on serotonin, but some of the original FGAs like the piperazine phenothiazine, perphenazine, also had such impacts (though proportionately higher dopamine 1 and 2 receptor blockade to the serotonin blockage $)^{17}$ p108-9. Based on extensive practice experience, perphenazine, for example, appeared to be effective and have lower risks of extrapyramidal symptoms (EPS) because those EPS generally occurred after the advent of the antipsychotic effects, meaning the doses could be dropped. Tardive dyskinesia was a clinical rarity. The same experience applies to SGAs, too.

However, these SGAs drugs have had their own problems. For example, closapine runs the risk of bone marrow suppression and in the USA monitoring (e.g., monthly) is necessary. Several apparently are linked with metabolic syndrome (and the FGAs often also had those problems). One example is olanzapine, an example of a drug with know increased risks of weight gain and diabetes. ${ }^{204-207}$ But the essence is whether the risk of tardive dyskinesia has been any lower or are some of the older typical neuroleptics like chlorpromazine in sedation and perphenazine as safe or safer because they are not selective for Dopamine 2 or Dopamine 2/3 receptors. The jury is not fully in this regard but studies such as CATIE have enlightened a little. ${ }^{208-213}$ I postulate that ultimately there will be a differential risk for TD amongst these SGAs partly based on higher selectivity for the Dopamine 2 or $2 / 3$ receptors compared with the dopamine 1 family. ${ }^{214-218}$

\section{The correlation of moreTD with duration of treatment and higher dosage}

In regard to dosing, the general rule of the higher the dose and the longer the duration certainly applies in increasing TD risk. Ultimately, I suspect that even more important is using too high a dose for that particular individual for that duration of time: Inappropriate doses create greater risk because the correct dose should actually overall have been lower. A further preliminary theoretical postulate is put forward that the tardive dyskinesia effects are predominantly due to Dopamine 2 (or 3 as it is part of the same receptor family). If this were so, dopamine blocking drugs that are less selective (acting on dopamine 1 as well) should produce less risk of tardive dyskinesia than selective dopamine 2 (or 3) neuroleptic agents. However, the author has previously proposed that based on epidemiological prevalence across countries, the broader actions of both Dopamine 1 and 2 blocking effects versus dopamine selectivity at the Dopamine 2 or $2 / 3$ levels are significantly protective for the development of tardive dyskinesia: it appears that certain neuroleptics could then show greater TD risk including haloperidol and metoclopramide because they are dopamine 2 or $2 / 3$ selective. This is in contrast to closapine, and the phenothiazines like perphenazine, and possibly quetiapine and olanzapine that appear less dopamine selective and may be more protective. A difficult drug to assess is the SGA aripiprazole because though selective for D2, it is a dopamine partial agonist and so may have different effects in diminishing the supersensitivity. This data is provided by a current Table, and showing that the current clinical case reports ostensibly support this hypothesis. This may have major implications in clinical choice of neuroleptic for patients at risk.

\section{Perspective}

So effectively, as I see it, it's not "at what dose"? The answer really is "at the correct dose for that patient at that time taking into account all other features". IMHO, patient individualization is important after applying the general rules for dosing. If there is a separate indication for buspirone, and there often is, then it's appropriate to prescribe it. But I do not think justifying any medication on an off-chance that it might help is logical at this point. It needs to be formally studied. Aripiprazole with its dopamine partial agonism should theoretically have had a lower risk, but that may not be true. Results have been mixed and there are reports of TD with it. The problem may be its selectivity, and at this point it appears that drugs such as closapine, olanzapine and quetiapine may be less selective at the dopamine receptor level. Also, any more sedative neuroleptic may produce lower risk, possibly because they are less likely to be "overdosed" and quetiapine fits that. Baseline TD rates with quetiapine are low, even compared to other second-generation antipsychotics.

One more component: Many patients have been on multiple neuroleptics. Consequently, it is difficult to single out a specific neuroleptic as causing the problem such as TD. However, it may be forensically easier to attribute the TD predominantly to a particular neuroleptic based on the dose, duration and onset of the TD, and the progression of the condition. Nevertheless, multiple neuroleptics complicate assessments of improvement or deterioration as other factors like assessing dose equivalents, pharmacodynamic interactions and natural history plus most importantly duration of the improvement or deterioration after the change, make interpretations difficult. First Generation Antipsychotics: The Typicals cannot be given an accurate TD rate because of their great variability. Quoted rates such as 3-5\% per year depending on age and diagnosis of population and choice of drug (e.g., TD with haloperidol is likely much higher than phenothiazines) with a plateau of $25 \%$ or so, are very speculative. ${ }^{136,219-237}$ 
Pharmacodynamically, drugs also might epidemiologically lower their risk of inducting TD. One variable is based on the postulated lowering of their propensity for acute EPS, and a second is the extent of rapid dissociation from the dopamine receptors. These, therefore, may be pertinent considerations. Overall, patients treated with conventional antipsychotics may be twice or even ten times as likely to develop definitive tardive dyskinesia than those with atypical antipsychotics, ${ }^{225,223,229,231,232}$ but such epidemiological studies might be flawed because individual drug differences may be more pertinent than specific class.

All these comments on TD risk applying neuroleptic propensity are partially supported by the published literature. However, there are often contradictions. It's interesting looking at the early work and predictions on TD ${ }^{200,234,238-250}$ compared with the most recent ideas. ${ }^{20,48,101,152,154,210,211,216-219,251-284}$ These latter ideas have taken into account clarity on genes and genetics of TD where at best the jury is undecided, and also still show contradictory data. What I have learned from this is most of the studies showing treatment effects of improving TD do not show profound, consistent and maintained effects. Many also show worsening or are marginal. ${ }^{34-41,63,68-70,74-98,101-124}$ By contrast, one can confidently expect consistently positive results this with highdose buspirone. Therefore, respectfully, it should be the drug of choice in TD management at this stage, despite the lack of large amounts of data at this point. And that treatment has a consistent basis for its management based on dopamine partial agonism and not specifically hitting Dopamine $2 / 3$ receptors as far as is known. ${ }^{285}$

\section{Neuroleptic choice}

We should choose neuroleptics that act on both Dopamine 1 and Dopamine 2 receptors non-selectively. Obviously, psychoactive compounds like cocaine and amphetamine have direct actions on dopamine and should be avoided. It may be that some nutritional substances may aggravate. Vitamin B6 may diminish Sinemet's effectiveness in Parkinson's disease, and we've seen one B6 case that did that in TD.

\section{Prophylaxis}

There's a possibility that the risk of development of TD could be lessened by prescribing buspirone prophylactically to prevent the onset of the TD. Some might consider using it for prevention as worthwhile, but the data is not yet available: I would be cautious at this stage and buspirone should be studied possibly double blind in a neuroleptic prescribed population (in this instance, a double blind study of adjunctive buspirone prophylaxis should be ethical because there is a genuine question of efficacy and balance of risks and benefits). However, we've also seen that there is great variation amongst the different neuroleptics in their dopamine profiles (and also other differences like extent of serotonin activity, and risks of metabolic syndrome). So any placebo controlled buspirone as adjunct study in TD prophylaxis must also look at which neuroleptics are to be chosen. This could be very expensive. An animal model also supports the effects of buspirone on dopamine receptors and this could contribute to concepts of prophylaxis as well as management. ${ }^{63}$ A second animal model is even more specific for buspirone reversing haloperidol sensitivity in rats. ${ }^{286}$

The question of dosage is also pertinent for such a study. Although buspirone is safe in doses of up to $60 \mathrm{mg}$ per day based on the millions of patients that have used it, like all medications it is not completely benign, it costs money, and polypharmacy (buspirone plus the neuroleptics) has other risks (drug interactions, non-adherence risk, etc.). But there may be other reasons to use buspirone in this population (for anxiety treatment acutely/directly). Also lower doses may not have these effects in any event. ${ }^{287}$ Additionally, doses like $120 \mathrm{mg} /$ day may not at this point be justified prophylactically as add-on therapy to neuroleptics until the lower does study has been initiated (although they could run concurrently). With the SGAs being available, certainly the risk is less than it was on FGAs. But without stronger evidence supporting its use for TD prevention, I'm just not sure it's worth it.

\section{Maxims}

I've applied some rather obvious maxims for many years. However, they could be argued to be not easily provable except with an enormous epidemiological study:

i. For the appropriate patient, we should prescribe the right dose, of the correct drugs, for the correct diagnoses, taking into account the severity of the condition at that time.

ii. Furthermore, we should prescribe these medications for the optimal duration in the appropriate frequencies while taking into account other interactions and applying careful monitoring and including the whole ethicobiopsychofamiliosociocultural approach, as well as evaluating individual differences in pharmacokinetics and pharmacodynamics. ${ }^{56}$

iii. Under these ideal conditions of \#1 and \#2, we should markedly lower the incidence of any significant and extended-duration side-effects, and, moreover, markedly increase pharmacological responsiveness. That reflects the approach of Innovative Psychopharmacotherapy. ${ }^{17,28}$

Since then our choice appears to have been justified, because high dose buspirone appears safe and effective in tardive dyskinesia. Nevertheless, this is not based on double-blind data, and such use does not preclude what may be rare problems with high dose buspirone, that are as yet unreported. Of course, this treatment is out-of-labeling, like much of what is prescribed in a specialist setting. Furthermore, there is no approved drug for TD so that automatically makes any treatment for TD out-of-labeling. Care and monitoring, and treating the whole patient, are always necessary, as with any treatment.

\section{Acknowledgments}

None.

\section{Conflicts of interest}

Author declare there are no conflicts of interest.

\section{Funding}

None.

\section{References}

1. Heilbrun K, Locklair B. Forensic assessment of juveniles. In Heilbrun $\mathrm{K}$, et al. (Eds.), APA handbook of psychology and juvenile justice. American Psychological Association, Washington DC. 2016. p.345-363.

2. Neppe VM. High-dose buspirone in case of tardive dyskinesia. Lancet. 1989;2(8677):1458.

3. Kovacic B, Domino EF. A monkey model of tardive dyskinesia (TD): evidence that reversible TD may turn into irreversible TD. $J$ Clin Psychopharmacol. 1982;2(5):305-307.

4. Leblhuber F, Reisecker F, Bengesser G. Tiapride in the treatment of irreversible tardive dyskinesia initial experiences. Z Gerontol. 1987;20(1):49-51 
5. Crane GE. Dyskinesia and neuroleptics. Arch Gen Psychiatry 1968;19(6):700-703.

6. Tye NC, Horsman L, Wright FC, et al. Differential enhancement of locomotor activity by dopamine agonists following chronic neuroleptic treatment: an animal model of tardive dyskinesia. Eur J Pharmacol. 1979;55(1):103-107.

7. Pycock C, Tarsy D, Marsden CD. Inhibition of circling behavior by neuroleptic drugs in mice with unilateral 6-hydroxydopamine lesions of the striatum. Psychopharmacologia. 1975;45(2):211-219.

8. Ellenbroek BA, Peeters BW, Honig WM, et al. The paw test: a behavioural paradigm for differentiating between classical and atypical neuroleptic drugs. Psychopharmacology. 1987;93(3):343-348.

9. Deniker P. From chlorpromazine to tardive dyskinesia (brief history of the neuroleptics). Psychiatr J Univ Ott. 1989;14(1):253-259.

10. Bourgeois M, Boueilh P, Tignol J. Spontaneous dyskinesia in the elderly and tardive dyskinesia of neuroleptics. A survey among 270 patients (author's transl). Encephale. 1980;6(1):37-39.

11. Rimski B, Bokonjic N. Clinical effect of largactil on dyskinesia. Med Arh. 1955;9(5):127-137.

12. Tatlow WF, Fisher CM, Dobkin AB. The clinical effects of chlorpromazine on dyskinesia. Can Med Assoc J. 1954;71(4):380-381.

13. Janssen P. The "social chemistry" of pharmacological discovery: the haloperidol story. An interview with Dr. Paul Janssen, January 21, 1986. Interview by Stanley Einstein. Int J Addict. 1992;27(3):331-346.

14. Granger B. The discovery of haloperidol. Encephale. 1999;25(1):59-66.

15. Gilbert MM. Haloperidol in severe facial dyskinesia. Case report. Dis Nerv Syst . 1969;30(7):481-482.

16. Bateman DN, Dutta DK, McClelland HA, et al. Metoclopramide and haloperidol in tardive dyskinesia. Br J Psychiatry. 1979;135:505-508 .

17. Neppe VM. Curing the incurable. Cry the Beloved Mind: A Voyage of Hope, Brainquest Press, washington, USA. 1999. p.311-343.

18. Neppe VM. Innovative Psychopharmacotherapy. (Revised 1st edn), Raven Press, New York, USA. 1990.

19. Neppe VM. Innovative Psychopharmacotherapy. (1st edn), Raven Press, Newyork, USA. 1989.

20. Moss LE, Neppe VM, Drevets WC. Buspirone in the treatment of tardive dyskinesia. J Clin Psychopharm. 1993;13(3):204-209.

21. Neppe VM. Clinical applications of the STRAW measures of severity and frequency of involuntary movements examination in tardive dyskinesia and movement disorders. 2014. P. 19

22. Moss LE, Neppe VM, Drevets WC. Buspirone in the treatment of tardive dyskinesia. J Clin Psychopharmacol. 1993;13(3):204-209.

23. Dhavalshankh AG1, Jadhav SA, Gaikwad RV, et al. Effects of buspirone on dopamine dependent behaviours in rats. Indian J Physiol Pharmacol. 2007;51(4):375-386.

24. Jadhav SA, Gaikwad RV, Gaonkar RK, et al. Dose-dependent response of central dopaminergic systems to buspirone in mice. Indian J Exp Biol. 2008;46(10):704-714

25. Young KA, Zavodny R, Hicks PB. Subchronic buspirone, mesulergine, and ICS 205-930 lack effects on D1 and D2 dopamine binding in the rat striatum during chronic haloperidol treatment. J Neural Transm Gen Sect. 1991;86(3):223-228.

26. Leggio GM, Camillieri G, Platania CB, et al. Dopamine D3 receptor is necessary for ethanol consumption: an approach with buspirone. Neuropsychopharmacology. 2014; 39(8):2017-2028.

27. Maskall DD, Zis AP, Lam RW, et al. Prolactin response to buspirone challenge in the presence of dopaminergic blockade. Biol Psychiatry. 1995;38(4):235-239.
28. washington, USA

29. Press, New York, USA.

30. Neppe VM, Sindorf J .Buspirone treatment of tardive dyskinesia. Abstracts Amer Psychiat Assoc Meeting. New York, USA. 1990.

31. Neppe VM. The electrical-chemical dichotomy: A journey of two continents. In: Ban TA, et al. (Eds.) The History of Psychopharmacology Autographical Accounts. Reflections in Twentieth-Century Psychopharmacology. Animula. 2004;4:455-461.

32. Neppe VM, Young Z. Buspirone as a new treatment for attention deficit disorder and aggression in children and adolescents. Australian $J$ of Psychopharmacology. 2003;10:47-56.

33. Howland RH. Drug therapies for tardive dyskinesia: Part 1. J Psychosoc Nurs Ment Health Serv. 2011;49(6):13-16.

34. Goff DC, Midha KK, Brotman AW, et al. An open trial of buspirone added to neuroleptics in schizophrenic patients. J Clin Psychopharmacol. 1991;11(3):193-197.

35. Kazamatsuri H, Chien C, Cole JO. Treatment of tardive dyskinesia. Clinical efficacy of a dopamine-depleting agent, tetrabenazine. Arch Gen Psychiatry. 1972;27(1):95-99.

36. Kazamatsuri H, Chien CP, Cole JO. Long-term treatment of tardive dyskinesia with haloperidol and tetrabenazine. Am J Psychiatry. 1973;130(4):479-483.

37. Snell AP, Cleary M, Sambrook M. Treatment of tardive dyskinesia with choline and tetrabenazine. Postgrad Med J. 1980;56(659):663-664.

38. Watson MW, Skelton D, Jamali F. Treatment of tardive dyskinesia: preliminary report on use of tetrabenazine. Can J Psychiatry. 1988;33(1):11-13

39. Ondo WG, Hanna PA, Jankovic J. Tetrabenazine treatment for tardive dyskinesia: assessment by randomized videotape protocol. Am J Psychiatry. 1999;156(8):1279-1281.

40. Sharma H. Treatment of Tardive Dyskinesia by tetrabenazine, clonazepam and vitamin E. Indian J Psychiatry. 2009;51(2):162-163.

41. Leung JG, Breden EL. Tetrabenazine for the treatment of tardive dyskinesia. Ann Pharmacother. 2011;45(4):525-531.

42. Koch HJ, Szecsey A, Vogel M. Successful therapy of tardive dyskinesia in a 71-year-old woman with a combination of tetrabenazine, olanzapine and tiapride. Int J Clin Pract. 2003;57(2):147-149.

43. Duvoisin RC. Reserpine for tardive dyskinesia. $N$ Engl $\mathrm{J}$ Med. 1972;286(11):611

44. Crane GE. Mediocre effects of reserpine on tardive dyskinesia. $N$ Engl J Med. 1973;288(2):104-105.

45. Peters HA, Daly RF, Sato S. Reserpine for tardive dyskinesia. $N$ Engl J Med. 1972;286(2):106.

46. Shore PA. The mechanism of norepinephrine depletion by reserpine, metaraminol and related agents. The role of monoamine oxidase. Pharmacol Rev. 1966;18(1):561-568.

47. Enero MA, Langer SZ. Influence of reserpine-induced depletion of noradrenaline on the negative feed-back mechanism for transmitter release during nerve stimulation. Br J Pharmacol. 173;49(2):214-225.

48. Luchelli Fortis MA, Langer SZ. Reserpine-induced depletion of the norepinephrine stores: is it a reliable criterion for the classification of the mechanism of action of sympathomimetic amines? J Pharmacol Exp Ther. 1974;188(3):640-653.

49. Ye M, Tang W, Liu L. Prevalence of tardive dyskinesia in chronic male inpatients with schizophrenia on long-term clozapine versus typical antipsychotics. Int Clin Psychopharmacol. 2014;29(6):318-321. 
50. Lieberman J, Johns C, Cooper T. Clozapine pharmacology and tardive dyskinesia. Psychopharmacology. 1989;99:54-59.

51. Gerlach J, Simmelsgaard H. Tardive dyskinesia during and following treatment with haloperidol, haloperidol+ biperiden, thioridazine, and clozapine. Psychopharmacology. 1978;59(2):105-112.

52. Pi EH, Simpson GM. Atypical neuroleptics: clozapine and the benzamides in the prevention and treatment of tardive dyskinesia. Mod Probl Pharmacopsychiatry. 1983;21:80-86.

53. Small JG, Milstein V, Marhenke JD. Treatment outcome with clozapine in tardive dyskinesia, neuroleptic sensitivity, and treatment-resistant psychosis. J Clin Psychiatry. 1987; 48(7):263-267.

54. Naber D, Leppig M, Grohmann R. Efficacy and adverse effects of clozapine in the treatment of schizophrenia and tardive dyskinesia-a retrospective study of 387 patients. Psychopharmacology. 1989. p.73-76.

55. Wirshing WC, Phelan CK, van Putten T. Effects of clozapine on treatment-resistant akathisia and concomitant tardive dyskinesia. J Clin Psychopharmacol. 1990;10(5):371-373.

56. Bajulaiye R, Addonizio. Clozapine in the treatment of psychosis in an 82-year-old woman with tardive dyskinesia. J Clin Psychopharmacol. 1992;12(5):364-365.

57. Neppe VM. Editorial Opinion: Principles of prescribing practice in psychiatry and neuropsychiatry. $J$ Psychol Clin Psychiatry. 2016;5(6):1-6.

58. See RE, Lynch AM, Sorg BA. Subchronic administration of clozapine, but not haloperidol or metoclopramide, decreases dopamine D2 receptor messenger RNA levels in the nucleus accumbens and caudate-putamen in rats. Neuroscience. 1996;72(1):99-104.

59. Harrold MW, Sriburi A, Matsumoto K, et al. The interaction of ammonium, sulfonium, and sulfide analogues of metoclopramide with the dopamine D2 receptor. J Med Chem. 1993;36(21):3166-3170.

60. Neppe VM. Ethics and informed consent for double-blind studies on the acute psychotic. Medical Psychiatric Correspondence: A Peer Reviewed Journal Model Copy. 1990;1(1):44-45.

61. Neppe VM. Double blind studies in Medicine: perfection or imperfection? Telicom. 2007;20(6):13-23.

62. Neppe V. From generic substitutions to nutraceuticals: Control, care, countries and choices (Section 2). Telicom. 2008;21(5):34-55.

63. Neppe V. A voyage into generic substitution and beyond (Section 1) Telicom. 2008;21(4):41-59.

64. Queiroz CM, Frussa Filho R. Effects of buspirone on an animal mode of tardive dyskinesia. Prog Neuropsychopharmacol BiolPsychiatry. 1999;23(8):1405-1418

65. Gammans RE, Mayol RF, LaBudde JA. Metabolism and disposition of buspirone. Am J Med. 1986;80(3):41-51.

66. Zhu MI, Zhao W, Jimenez H, et al. Cytochrome P450 3A-mediated metabolism of buspirone in human liver microsomes. Drug Metab Dispos. 2005;33(4):500-507.

67. Viveros OH, Arqueros L, Kirshner N. Mechanism of secretion from the adrenal medulla. VI. effect of reserpine on the dopamine -hydroxylase and catecholamine content and on the buoyant density of adrenal storage vesicles. Mol Pharmacol. 1971;7(4):434-443.

68. Dolphin A, Jenner P, Marsden CD. Proceedings: the mechanism of the effect of dopamine-beta-hydroxylase inhibitor FLA-63 on the L-DOPA reversal of reserpine akinesia. Br J Pharmacol. 1975;54(2):246-247.

69. Fahn S. Treatment of tardive dyskinesia with combined reserpine and alpha-methyltyrosine. Trans Am Neurol Assoc. 1978;103:100-103.

70. Huang CC, Wang RI, Hasegawa A. Evaluation of reserpine and alphamethyldopa in the treatment of tardive dyskinesia. Psychopharmacol Bull. 1980;16(3):41-43
71. Huang CC, Wang RI, Hasegawa A. Reserpine and alpha-methyldopa in the treatment of tardive dyskinesia. Psychopharmacology. 1981;73(4):359-362.

72. Alecu C, Marcutiu V, Pruskauer Apostol B. Clonazepam in the treatment of tardive dyskinesia. Rev Med Interna Neurol Psihiatr Neurochir Dermatovenerol Neurol Psihiatr Neurochir. 1984;29(4):285-289.

73. Sarbulescu A, Alexandrescu L, Georgescu MJ. Comparative study of two benzodiazepines ("diazepam" versus "nitrazepam") in the treatment of postneuroleptic tardive dyskinesia. Neurol Psychiatr (Bucur). 1986;24(3):189-193.

74. Thaker GK, Nguyen JA, Strauss ME. Clonazepam treatment of tardive dyskinesia: a practical GABAmimetic strategy. Am J Psychiatry. 1990;147(4):445-451

75. Soares KV, McGrath JJ. Vitamin E for neuroleptic-induced tardive dyskinesia. Cochrane Database Syst Rev. 2001;4:CD000209.

76. Soares Weiser K, Maayan N, McGrath J. Vitamin E for neurolepticinduced tardive dyskinesia. Cochrane Database Syst Rev. 2011;2:CD000209.

77. Lohr JB, Cadet JL, Lohr MA. Vitamin E in the treatment of tardive dyskinesia: the possible involvement of free radical mechanisms. Schizophr Bull. 1988;14(2):291-296.

78. Cadet JL, Lohr JB. Possible involvement of free radicals in neurolepticinduced movement disorders. Evidence from treatment of tardive dyskinesia with vitamin E. Ann N Y Acad Sci. 1989;570:176-185.

79. Elkashef AM, Ruskin PE, Bacher N (1990) Vitamin E in the treatment of tardive dyskinesia. Am J Psychiatry 147(4): 505-506.

80. Shriqui CL, Bradwejn J, Annable L (1992) Vitamin E in the treatment of tardive dyskinesia: a double-blind placebo-controlled study. Am J Psychiatry 149(3): 391-393.

81. Egan MF, Hyde TM, Albers GW (1992) Treatment of tardive dyskinesia with vitamin E. Am J Psychiatry 149(6): 773-777.

82. Spivak B, Schwartz B, Radwan M, Weizman A (1992) Alpha-Tocopherol treatment for tardive dyskinesia. J Nerv Ment Dis 180(6): 400-401.

83. Peet M, Laugharne J, Rangarajan N, Reynolds GP (1993) Tardive dyskinesia, lipid peroxidation, and sustained amelioration with vitamin E treatment. Int Clin Psychopharmacol 8(3): 151-153.

84. Holmes VF, D’Alli R, Schweickert L, et al. Vitamin E treatment of tardive dyskinesia. Am J Psychiatry. 1993;150(6):991.

85. Corrigan FM, Van Rhijn AG, Mackay AV, et al. Vitamin E treatment of tardive dyskinesia. Am J Psychiatry. 1993;150(6):991-992.

86. Akhtar S, Jajor TR, Kumar S. Vitamin E in the treatment of tardive dyskinesia. J Postgrad Med. 1993;39(3):124-126.

87. Adler LA, Peselow E, Rotrosen J, et al. Vitamin E treatment of tardive dyskinesia. Am J Psychiatry. 1993;150(9):1405-1407.

88. Lam LC, Chiu HF, Hung SF. Vitamin E in the treatment of tardive dyskinesia: a replication study. J Nerv Ment Dis. 1994;182(2):113-114.

89. Dabiri LM, Pasta D, Darby JK, et al. Effectiveness of vitamin E for treatment of long-term tardive dyskinesia. Am $J$ Psychiatry. 1994;151(6):925-926.

90. Lohr JB, Caligiuri MP. A double-blind placebo-controlled study of vitamin E treatment of tardive dyskinesia. J Clin Psychiatry. 1996;57(4):167-173.

91. Dorevitch A, Kalian M, Shlafman M, et al. Treatment of long-term tardive dyskinesia with vitamin E. Biol Psychiatry. 1997;41(1):114-116.

92. Adler LA, Edson R, Lavori P, et al. Long-term treatment effects of vitamin E for tardive dyskinesia. Biol Psychiatry. 1998;43(12):868-872. 
93. Sajjad SH. Vitamin E in the treatment of tardive dyskinesia: a preliminary study over 7 months at different doses. Int Clin Psychopharmacol. 1998;13(4):147-155.

94. Barak Y, Swartz M, Shamir E, et al. Vitamin E (alpha-tocopherol) in the treatment of tardive dyskinesia: a statistical meta-analysis. Ann Clin Psychiatry. 1998;10(3):101-105.

95. Boomershine KH, Shelton PS, Boomershine JE. Vitamin E in the treatment of tardive dyskinesia. Ann Pharmacother. 1999;33(11):1195-1202.

96. Elkashef AM, Wyatt RJ. Tardive dyskinesia: possible involvement of free radicals and treatment with vitamin E. Schizophr Bull. 1999;25(4):731-740.

97. Michael N, Sourgens H, Arolt V, et al. Severe tardive dyskinesia in affective disorders: treatment with vitamin $\mathrm{E}$ and C. Neuropsychobiology. 2002;46(Suppl 1):28-30.

98. Adler LA, Rotrosen J, Edson R, et al. Vitamin E treatment for tardive dyskinesia. Veterans Affairs Cooperative Study \#394 Study Group. Arch Gen Psychiatry. 1999;56(9):836-841.

99. Zhang XY, Zhou DF, Cao LY, et al. The effect of vitamin E treatment on tardive dyskinesia and blood superoxide dismutase: a double-blind placebo-controlled trial. J Clin Psychopharmacol. 2004;24(1):83-86.

100. Yassa R. Carbamazepine in the treatment of tardive dyskinesia. Am J Psychiatry. 1986;143(9):1191.

101. LaHoste GJ, Wigal T, King BH, et al. Carbamazepine reduces dopaminemediated behavior in chronic neuroleptic-treated and untreated rats: implications for treatment of tardive dyskinesia and hyperdopaminergic states. Exp Clin Psychopharmacol. 2000;8(1):125-132.

102. Lerner V, Miodownik C. Motor symptoms of schizophrenia: is tardive dyskinesia a symptom or side effect? A modern treatment. Curr Psychiatry Rep. 2011;13(4):295-304.

103. Zivković SA, Costa G, Bond G, et al. Treatment of tardive dyskinesia with levetiracetam in a transplant patient. Acta Neurol Scand. 2008;117(5):351-353.

104. Araujo NP, Abílio VC, Silva RH, et al. Effects of topiramate on ora dyskinesia induced by reserpine. Brain Res Bull. 2004;64(4):331-337.

105. Peixoto MF, Abílio VC, Silva RH, et al. Effects of valproic acid on an animal model of tardive dyskinesia. Behav Brain Res. 2003;142(1-2):229-233.

106. Bhattacharya SK, Bhattacharya D, Sairam K, et al. Effect of Withania somnifera glycowithanolides on a rat model of tardive dyskinesia. Phytomedicine. 2002;9(2):167-170.

107. Simpson GM. The treatment of tardive dyskinesia and tardive dystonia J Clin Psychiatry. 2000;61(Suppl 4):39-44.

108. Bhattachary SK, Bhattacharya D, Muruganandam AV. Effect of Emblica officinalis tannoids on a rat model of tardive dyskinesia. Indian $J$ Exp Biol. 2000;38(9):945-947.

109. Soares KV, McGrath JJ. The treatment of tardive dyskinesia--a systematic review and meta-analysis. Schizophr Res. 1999;39(1):1-16.

110. Gupta S, Mosnik D, Black DW, et al. Tardive dyskinesia: review of treatments past, present, and future. Ann Clin Psychiatry. 1999;11(4):257-266.

111. Egan MF, Apud J, Wyatt RJ. Treatment of tardive dyskinesia. Schizophr Bull. 1997;23(4):583-609.

112. Gardos G, Cole JO. The evaluation and treatment of neuroleptic-induced movement disorders. Harv Rev Psychiatry. 1995;3(3):130-139.

113. Montastruc JL, Llau ME, Rascol O, et al. Drug-induced parkinsonism: a review. Fundam Clin Pharmacol. 1994;8(4):293-306.

114. Feltner DE, Hertzman M. Progress in the treatment of tardive dyskinesia: theory and practice. Hosp Community Psychiatry. 1993;44(1):25-34.
115. Meltzer HY. Treatment of the neuroleptic-nonresponsive schizophrenic patient. Schizophr Bull. 1992;18(3):515-542.

116. Dommisse J. Nutritional treatment of tardive dyskinesia. Am J Psychiatry. 1991;148(2):279.

117. Casey DE. Tardive dyskinesia: epidemiologic factors as a guide for prevention and management. Adv Biochem Psychopharmacol. $1985 ; 40: 15-24$.

118. Piccinin GL, Piccirilli M, Rizzo PA. Treatment of tardive dyskinesia caused by neuroleptics. Riv Neurol. 1984;54(3):199-215.

119. Andrade LA, Bertolucci PH, Pereira JS. Tardive dyskinesia: I. Physiopathology and treatment. Arq Neuropsiquiatr. 1984;42(4):362-370.

120. Tegeler J, Wöller W. Therapeutic measures in tardive dyskinesia. Fortschr Neurol Psychiatr. 1983;51(6):203-226.

121. Fahn S. Long-term treatment of tardive dyskinesia with presynaptically acting dopamine-depleting agents. Adv Neurol . 1983;37: 267-276.

122. Fahn S. Treatment of tardive dyskinesia: use of dopamine-depleting agents. Clin Neuropharmacol. 1983;6(2):151-158.

123. Olajossy M. Tardive dyskinesia: problems of pathogenesis, treatment and prevention. Psychiatr Pol. 1980;14(6):621-625.

124. Jus A, Jus K, Fontaine P. Long term treatment of tardive dyskinesia. J Clin Psychiatry. 1979;40(2):72-77.

125. Bourgeois M. Tardive Dyskinesia induced by neuroleptics: a survey of 3140 patients in a psychiatric hospital. Encephale. 1977;3(4):299-320.

126. Haggstrom JE, Andersson U, Gunne LM. Bromocriptine in tardive dyskinesia. Pharmacopsychiatria. 1982;15(5):161-163.

127. Tamminga CA, Chase TN. Bromocriptine and CF 25-397 in the treatment of tardive dyskinesia. Arch Neurol. 1980;37(4):204-205.

128. Lieberman JA, Alvir J, Mukherjee S, et al. Treatment of tardive dyskinesia with bromocriptine. A test of the receptor modification strategy. Arch Gen Psychiatry. 1989; 46(10):908-913.

129. Ankenman R. The combination of amantadine and neuroleptics plus time may cure tardive dyskinesia. J Neuropsychiatry Clin Neurosci. 1989;1(1):96-97.

130. Freudenreich O, McEvoy JP. Added amantadine may diminish tardive dyskinesia in patients requiring continued neuroleptics. J Clin Psychiatry. 1995;56(4):173.

131. Decker BL, Davis JM, Jonowsky DS, et al. Amantadine hydrochloride treatment of tardive dyskinesia. $N$ Engl J Med. 1971;285(15):860.

132. Allen RM. Palliative treatment of tardive dyskinesia with combination of amantadine-neuroleptic administration. Biol Psychiatry. 1982;17(6):719-727.

133. Angus S, Sugars J, Boltezar R, et al. A controlled trial of amantadine hydrochloride and neuroleptics in the treatment of tardive dyskinesia. $J$ Clin Psychopharmacol. 1997; 17(2):88-91.

134. Casey DE, Gerlach J, Bjorndal N. Levodopa and receptor sensitivity modification in tardive dyskinesia. Psychopharmacology. 1982;78(1):89-92.

135. Bannet J, Belmaker RH, Ebstein RP. The effect of drug holidays in an animal model of tardive dyskinesia. Psychopharmacology. 1980;69(2):223-224.

136. Fairbairn AF, Rowell FJ, Hui SM, et al. Serum concentration of depo neuroleptics in tardive dyskinesia. Br J Psychiatry. 1983;142:579-583.

137. Gibson AC. Incidence of tardive dyskinesia in patients receiving depot neuroleptic injection. Acta Psychiatr Scand Suppl. 1981;291:111-116. 
138. Glazer WM, Kane JM. Depot neuroleptic therapy: an underutilized treatment option. J Clin Psychiatry. 1992;53(12):426-433.

139. Barnes TR, Wiles DH. Variation in oro-facial tardive dyskinesia during depot antipsychotic drug treatment. Psychopharmacology. 1983;81(4):359-362.

140. Jackson IV, Nuttall EA, Ibe IO, et al. Treatment of tardive dyskinesia with lecithin. Am J Psychiatry. 1979;136(11):1458-1460.

141. Wilbur K, Kulik AV, Brecht TC. Lecithin for tardive dyskinesia. Am J Psychiatry. 1982;139(10):1375.

142. Branchey MH, Branchey LB, Bark NM, et al. Lecithin in the treatment of tardive dyskinesia. Commun Psychopharmacol. 1979;3(5):303-307.

143. Gelenberg AJ, Doller WJC, Growdon JH. Choline and lecithin in the treatment of tardive dyskinesia: preliminary results from a pilot study. Am J Psychiatry. 1979;136(6):772-776.

144. Zeisel SH, Gelenberg AJ, Growdon JH, et al. Use of choline and lecithin in the treatment of tardive dyskinesia. Adv Biochem Psychopharmacol. 1980;24:463-470.

145. Perez CJ, Menendez I, Alvarez GJ, et al. Double-blind study of lecithin in the treatment of persistent tardive dyskinesia. Bol Asoc Med P R 1981;73(11):531-537.

146. Gelenberg AJ, Dorer DJ, Wojcik JD, et al. A crossover study of lecithin treatment of tardive dyskinesia. J Clin Psychiatry. 1990;51(4):149-153.

147. Lerner V, Kaptsan A, Miodownik C, et al. Vitamin B6 in treatment of tardive dyskinesia: a preliminary case series study. Clin Neuropharmacol. 1999;22(4):241-243.

148. Lerner V, Miodownik C, Kaptsan A, et al. Vitamin B6 treatment for tardive dyskinesia: a randomized, double-blind, placebo-controlled, crossover study. J Clin Psychiatry. 2007;68(11):1648-1654.

149. Strous RD, Kupchik M, Roitman S, et al. Comparison between risperidone, olanzapine, and clozapine in the management of chronic schizophrenia: a naturalistic prospective 12-week observational study. Hum Psychopharmacol. 2006;21(4):235-243.

150. Sacchetti E, Valsecchi P. Quetiapine, clozapine, and olanzapine in the treatment of tardive dyskinesia induced by first-generation antipsychotics: a 124-week case report. Int Clin Psychopharmacol. 2003;18(6):357-359.

151. Pi EH, Simpson GM. Atypical neuroleptics: clozapine and the benzamides in the prevention and treatment of tardive dyskinesia. Mod Probiew. 1983;21:80-86.

152. Meltzer HY. An overview of the mechanism of action of clozapine. $J$ Clin Psychiatry. 1994;55:47-52.

153. Goyal R, Devi SH. A case of aripiprazole induced tardive dyskinesia in a neuroleptic-naive patient with two years of follow up. Clin Psychopharmacol Neurosci. 2014; 12(1):69-71.

154. Lykouras L, Rizos E, Gournellis R. Aripiprazole in the treatment of tardive dyskinesia induced by other atypical antipsychotics. Prog Neuropsychopharmacol Biol Psychiatry. 2007;31(7):1535-1536.

155. Kang NR, Kim MD. Tardive dyskinesia: treatment with aripiprazole. Clin Psychopharmacol Neurosci. 2011;9(1):1-8.

156. Witschy JK, Winter AS. Improvement in tardive dyskinesia with aripiprazole use. Can J Psychiatry. 2005;50(3):188.

157. Taylor DM. Aripiprazole: a review of its pharmacology and clinical use. Int J Clin Pract. 2003;57(1):49-54.

158. Christensen AV, Nielsen IM. Dopaminergic supersensitivity: influence of dopamine agonists, cholinergics, anticholinergics, and drugs used for the treatment of tardive dyskinesia. Psychopharmacology 1979;62(2):111-116.
159. Tamminga CA, Thaker GK, Ferraro TN, et al. GABA agonist treatment improves tardive dyskinesia. Lancet. 1983;2(8341):97-98.

160. Thaker GK, Hare TA, Tamminga CA. GABA system: clinical research and treatment of tardive dyskinesia. Mod Probl Pharmacopsychiatry. $1983 ; 21: 155-167$

161. Gomez A, Troncoso San Martin E, Pesenti L. Hypersensitivity to apomorphine in rats treated with neuroleptics: a model of tardive dyskinesia. Rev Med Chil. 1982;110(4):319-322.

162. Su CJ, Xu XQ, Fan Y, et al. Aquaporin-4 knockout abolishes apomorphine-induced tardive dyskinesia following chronic treatment with neuroleptics. CNS Neurosci Ther . 2012;18(12):1024-1026.

163. Blum I, Munitz H, Shalev A, et al. Naloxone may be beneficial in the treatment of tardive dyskinesia. Clin Neuropharmacol. $1984 ; 7(3): 265-267$.

164. Buck OD, Havey P. Treatment of tardive dyskinesia with verapamil. $J$ Clin Psychopharmacol. 1988;8(4):303-304.

165. Cates M, Lusk K, Wells BG. Are calcium-channel blockers effective in the treatment of tardive dyskinesia? Ann Pharmacother. 1993;27(2):191-196.

166. Neppe VM. The clinical neuropharmacology of buspirone, in Innovative Psychopharmacotherapy. Raven Press, New York, USA. 1989. p.35-57.

167. Neppe VM. Buspirone : an anxioselective neuromodulator, in Innovative Psychopharmacotherapy. Raven Press, New York, USA. 1990. p.35-57.

168. Temple DI, Yevich JP, New JS. Buspirone: chemical profile of a new class of anxioselective agents.J Clin Psychiatry. 1982;43:4-9.

169. Elson MS. The new generation of serotonergic anxiolytics; possible clinical roles. Psychopathology. 1989;22(1):13-20.

170. Sprouse JS, Aghanjanian GK. (-)-Propranolol blocks the inhibition of serotonergic dorsal raphe cell firing by 5-HT1A selective 5-HT1A agonists. Eur J Pharmacol. 1986; 128(3):295-298.

171. Jeste DV, Wyatt RJ. Dogma disputed: is tardive dyskinesia due to postsynaptic dopamine receptor supersensitivity? J Clin Psychiatry. 1981;42(12):455-457.

172. Neppe VM, Close ER. Explaining psi phenomena by applying TDVP principles: A preliminary analysis. IQ Nexus Journal. 2015;7(3):7-129.

173. Palmer J, Neppe VM. Exploratory analyses of refined predictors of subjective ESP experiences and temporal Lobe Dysfunction in a neuropsychiatric population. European Journal of Parapsychology. 2004; 19:44-65.

174. Palmer J, Neppe VM. A controlled analysis of subjective paranormal experiences in temporal lobe dysfunction in a neuropsychiatric population. Journal of Parapsychology. 2003;67:75-97.

175. Gordon JH, Diamond BI. Antagonism of dopamine supersensitivity by estrogen: neurochemical studies in an animal model of tardive dyskinesia. Biol Psychiatry. 1981; 16(4):365-371.

176. Lee SH, Oh DY, Jung SC, et al. Neuroleptic drugs alter the dopamine transporter-mediated uptake and release of dopamine: a possible mechanism for drug-induced tardive dyskinesia. Pharmacol Res. 1997;35(5):447-450.

177. Kulkarni SK, Naidu PS. Tardive dyskinesia: An update. Drugs Today (Barc). 2001;37(2):97-119.

178. Kobiella A, Vollstädt-Klein S, Bühler M, et al. Human dopamine receptor D2/D3 availability predicts amygdala reactivity to unpleasant stimuli. Hum Brain Mapp. 2010; 31(5):716-726.

179. Sáiz PA1, García-Portilla MP, Arango C, et al. Genetic polymorphisms in the dopamine-2 receptor (DRD2), dopamine-3 receptor (DRD3), and dopamine transporter (SLC6A3) genes in schizophrenia: Data from an association study. Prog Neuropsychopharmacol Biol Psychiatry. 2010;34(1):26-31 
180. Levant B. The D3 dopamine receptor: neurobiology and potential clinical relevance. Pharmacol Rev. 1997;49(3):231-252.

181. Mahmoudi S, Lévesque D, Blanchet PJ. Upregulation of dopamine D3, not D2, receptors correlates with tardive dyskinesia in a primate model. Mov Disord. 2014;29(9):1125-1133.

182. Lahti RA, Evans DL, Stratman NC,et al. Dopamine D4 versus D2 receptor selectivity of dopamine receptor antagonists: possible therapeutic implications. Eur J Pharmacol. 1993;236(3):483-486.

183. Ozdemir E, Bagcivan I, Gursoy S. Role of $D(1) / D(2)$ dopamine receptors antagonist perphenazine in morphine analgesia and tolerance in rats. Bosn J Basic Med Sci . 2013;13(2):119-125.

184. Castro SW, Strange PG. Coupling of D2 and D3 dopamine receptors to G-proteins. FEBS Lett. 1993;315(3):223-226.

185. Chio CL, Lajiness ME, Huff RM. Activation of heterologously expressed D3 dopamine receptors: comparison with D2 dopamine receptors. $\mathrm{Mol}$ Pharmacol. 1994;45(1):51-60.

186. Potenza MN, Graminski GF, Schmauss C, et al. Functional expression and characterization of human D2 and D3 dopamine receptors. $J$ Neurosci. 1994;14(3 Pt 2):1463-1476.

187. Tang L, Todd RD, Heller A, et al. Pharmacological and functional characterization of D2, D3 and D4 dopamine receptors in fibroblast and dopaminergic cell lines. J Pharmacol Exp Ther. 1994;268(1):495-502.

188. Braun AR, Laruelle M, Mouradian MM. Interactions between D1 and D2 dopamine receptor family agonists and antagonists: the effects of chronic exposure on behavior and receptor binding in rats and their clinical implications. J Neural Transm (Vienna). 1997;104(4 5):341-362.

189. Boublik JH, Funder JW. Interaction of dopamine receptor ligands with subtypes of the opiate receptor. Eur J Pharmacol. 1984;107(1):11-16.

190. Blumberg AL, Wilson JW, Hieble JP. Neuroinhibitory effects of SK\&F 85174, a novel dopamine receptor agonist. J Cardiovasc Pharmacol. 1985;7(4):723-732.

191. Anden NE, Grabowska AM. Drug effects on pre and postsynaptic dopamine receptors. Adv Biochem Psychopharmacol. 1980;24:57-64.

192. al Tajir G, Chandler CJ, Starr BS, et al. Opposite effects of stimulation of D1 and D2 dopamine receptors on the expression of motor seizures in mouse and rat. Neuropharmacology. 1990;29(7):657-661.

193. Lidsky TI, Schneider JS. Neural mechanisms of tardive dyskinesia. Med Hypotheses. 1981;7(9):1117-1122.

194. Gunne LM, Andrén PE. An animal model for coexisting tardive dyskinesia and tardive parkinsonism: a glutamate hypothesis for tardive dyskinesia. Clin Neuropharmacol. 1993;16(1):90-95.

195. Lee HJ, Kang SG. Genetics of tardive dyskinesia. Int Rev Neurobiol. 2011;98:231-264

196. Li CT, Chou KH, Su TP, et al. Gray matter abnormalities in schizophrenia patients with tardive dyskinesia: a magnetic resonance imaging voxelbased morphometry study. PLoS One. 2013;8(8):e71034.

197. Dunayevich E, Chen CY, Marder SR, et al. Restrictive symptomatic inclusion criteria create barriers to clinical research in schizophrenia negative symptoms: an analysis of the CATIE dataset. Eur Neuropsychopharmacol. 2014;24(10):1615-1621.

198. https://en.wikipedia.org/wiki/Antipsychotic

199. Savelyeva MV, Baldenkov GN, Kaverina NV. Receptor binding potencies of chlorpromazine, trifluoperazine, fluphenazine and their 10-N-substituted analogues. Biomed Biochim Acta. 1998;47(12):1085-1087.

200. Borison RL, Shah C, White TH, et al. Atypical and typical neuroleptics and tardive dyskinesia. Psychopharmacol Bull. 1987;23(1):218-220.
201. See RE, Ellison G. Comparison of chronic administration of haloperidol and the atypical neuroleptics, clozapine and raclopride, in an anima model of tardive dyskinesia. Eur J Pharmacol. 1990;181(3):175-186.

202. Bishnoi M, Kumar A, Chopra K, et al. Comparative neurochemical changes associated with chronic administration of typical and atypical neuroleptics: implications in tardive dyskinesia. Indian $J$ Exp Biol. 2007;45(2):175-179.

203. Herman ZS, Huzarska M. Chronic treatment with atypical neuroleptics sulpiride and metoclopramide increases striatal enkephalins in rat brain. Pol J Pharmacol. 1993; 45(5-6):493-502.

204. Charfi F, Cohen D, Houeto JL,et al. Tardive dystonia induced by atypical neuroleptics: a case report with olanzapine. J Child Adolesc Psychopharmacol. 2004;14(1):149-152.

205. L'Italien GJ, Casey DE, Kan HJ, et al. Comparison of metabolic syndrome incidence among schizophrenia patients treated with aripiprazole versus olanzapine or placebo. J Clin Psychiatry.2007;68(10):1510-1516.

206. Lee NY, Kim SH, Jung DC, et al. The prevalence of metabolic syndrome in Korean patients with schizophrenia receiving a monotherapy with aripiprazole, olanzapine or risperidone. Prog Neuropsychopharmacol Biol Psychiatry. 2011;35(5):1273-1278.

207. Stroup TS, Byerly MJ, Nasrallah HA, et al. Effects of switching from olanzapine, quetiapine, and risperidone to aripiprazole on 10-year coronary heart disease risk and metabolic syndrome status: results from a randomized controlled trial. Schizophr Res. 2013;146(1-3):190-195.

208. Wani RA, Dar MA, Chandel RK, et al. Effects of switching from olanzapine to aripiprazole on the metabolic profiles of patients with schizophrenia and metabolic syndrome: a double-blind, randomized, open-label study. Neuropsychiatr Dis Treat. 2015;11:685-693.

209. Czobor P, Van Dorn RA, Citrome L, et al. Treatment adherence in schizophrenia: a patient-level meta-analysis of combined CATIE and EUFEST studies. Eur Neuropsychopharmacol. 2015;25(8):1158-1166.

210. Miller DD, McEvoy JP, Davis SM, et al. Clinical correlates of tardive dyskinesia in schizophrenia: baseline data from the CATIE schizophrenia trial. Schizophr Res. 2005; 80(1):33-43.

211. Tsai HT, Caroff SN, Miller DD, et al. A candidate gene study of Tardive dyskinesia in the CATIE schizophrenia trial. Am J Med Genet B Neuropsychiatr Genet. 2010;153B(1):336-340.

212. Yoshida K, Bies RR, Suzuki T, et al. Tardive dyskinesia in relation to estimated dopamine D2 receptor occupancy in patients with schizophrenia: analysis of the CATIE data. Schizophr Res. 2014;153(1-3):184-188.

213. Meltzer HY, Bobo WV. Interpreting the efficacy findings in the CATIE study: what clinicians should know. CNS Spectr. 2006;11(7 Suppl 7):14-24.

214. Casey DE. Implications of the CATIE trial on treatment: extrapyramidal symptoms. CNS Spectr. 2006;11(7 Suppl 7):25-31.

215. Correll CU, Schenk EM. Tardive dyskinesia and new antipsychotics. Curr Opin Psychiatry. 2008;21(2):151-156.

216. Peritogiannis V, Tsouli S. Can atypical antipsychotics improve tardive dyskinesia associated with other atypical antipsychotics? Case report and brief review of the literature. J Psychopharmacol. 2010;24(7):1121-1125.

217. Aggarwal S, Burnett P. Tardive dyskinesia with atypical antipsychotics in youth. Australas Psychiatry. 2013;21(5):507-508.

218. Pinninti NR, Faden J, Adityanjee A. Are Second-Generation Antipsychotics Useful in Tardive Dystonia? Clin Neuropharmacol. 2015;38(5):183-197.

219. Ryu S, Yoo JH, Kim JH, et al. Tardive dyskinesia and tardive dystonia with second-generation antipsychotics in non-elderly schizophrenic patients unexposed to first-generation antipsychotics: a cross-sectional and retrospective study. J Clin Psychopharmacol. 2015;35(1):13-21. 
220. Kinon BJ, Kollack-Walker S, Jeste D, et al. Incidence of tardive dyskinesia in older adult patients treated with olanzapine or conventional antipsychotics. J Geriatr Psychiatry Neurol. 2015;28(1):67-79.

221. Miller DD, Eudicone JM, Pikalov A, et al. Comparative assessment of the incidence and severity of tardive dyskinesia in patients receiving aripiprazole or haloperidol for the treatment of schizophrenia: a post hoc analysis. J Clin Psychiatry. 2007;68(12):1901-1906.

222. Correll CU, Kane JM. One-year incidence rates of tardive dyskinesia in children and adolescents treated with second-generation antipsychotics: a systematic review. J Child Adolesc Psychopharmacol. 2007;17(5):647-656.

223. van Harten PN, Hoek HW, Matroos GE, et al. Incidence of tardive dyskinesia and tardive dystonia in African Caribbean patients on longterm antipsychotic treatment: the Curacao extrapyramidal syndromes study V. J Clin Psychiatry. 2006;67(12):1920-1927.

224. Margolese HC, Chouinard G, Kolivakis TT, et al. Tardive dyskinesia in the era of typical and atypical antipsychotics. Part 2: Incidence and management strategies in patients with schizophrenia. Can J Psychiatry. 2005;50(11):703-714.

225. Kane JM. Tardive dyskinesia rates with atypical antipsychotics in adults prevalence and incidence. J Clin Psychiatry. 2004; 65(Suppl 9):16-20.

226. Dolder CR, Jeste DV. Incidence of tardive dyskinesia with typical versus atypical antipsychotics in very high risk patients. Biol Psychiatry. 2003;53(12):1142-1145.

227. Marshall DL, Hazlet TK, Gardner JS, et al. Neuroleptic drug exposure and incidence of tardive dyskinesia: a records-based case-control study. J Manag Care Pharm. 2002;8(4):259-265.

228. Linn GS, Lifshitz K, O Keeffe RT, et al. Increased incidence of dyskinesias and other behavioral effects of re-exposure to neuroleptic treatment in social colonies of Cebus apella monkeys. Psychopharmacology (Berl). 2001;153(3):285-294

229. Glazer WM. Review of incidence studies of tardive dyskinesia associated with typical antipsychotics. J Clin Psychiatry. 2000;61(Suppl 4):15-20.

230. Glazer WM. Expected incidence of tardive dyskinesia associated with atypical antipsychotics. J Clin Psychiatry. 2000;61(Suppl 4):21-26.

231. Jeste DV, Lacro JP, Palmer B, et al. Incidence of tardive dyskinesia in early stages of low-dose treatment with typical neuroleptics in older patients. Am J Psychiatry. 1999; 156(2):309-311.

232. Beasley CM, Dellva MA, Tamura RN, et al. Randomised doubleblind comparison of the incidence of tardive dyskinesia in patients with schizophrenia during long-term treatment with olanzapine or haloperidol. Br J Psychiatry. 1999;174:23-30.

233. Tollefson GD, Beasley CM, Tamura RN, et al. Blind, controlled, long-term study of the comparative incidence of treatment-emergent tardive dyskinesia with olanzapine or haloperidol. Am J Psychiatry. 1997;154(9):1248-1254.

234. Egan MF, Hyde TM, Kleinman JE, et al. Neuroleptic-induced vacuous chewing movements in rodents: incidence and effects of long-term increases in haloperidol dose. Psychopharmacology (Berl). 1995; 117(1):74-81

235. Harris MJ, Panton D, Caligiuri MP, et al. High incidence of tardive dyskinesia in older outpatients on low doses of neuroleptics. Psychopharmacol Bull. 1992;28(1):87-92.

236. Sandyk R. Increased incidence of neuroleptic-induced perioral movements in the rat by hyperglycemia. Int $J$ Neurosci. 1990;50(3-4):227-232.

237. Sandyk R, Fisher H. Increased incidence and severity of neurolepticinduced movement disorder in pinealectomized rats. Int $J$ Neurosci. 1989;48(3-4):303-308.

238. Barcia D, Pozo P, Ruiz ME, et al. [Evaluation of the incidence of tardive dyskinesias in 3 groups of patients treated with different neuroleptics] Actas Luso Esp Neurol Psiquiatr Cienc Afines. 1987;15(1):25-28.

239. Crane GE. Tardive dyskinesia in patients treated with major neuroleptics: a review of the literature. Am J Psychiatry. 1968;124(8):40-48.

240. Mallya A, Jose C, Baig M, et al. Antiparkinsonics, neuroleptics, and tardive dyskinesia. Biol Psychiatry. 1979;14(4):645-649.

241. Perris C, Dimitrijevic P, Jacobsson L, et al. Tardive dyskinesia in psychiatric patients treated with neuroleptics. $\mathrm{Br} J$ Psychiatry. 1979;135:509-514.

242. Lin HN, Chen CY. Tardive dyskinesia in patients treated with antipsychotics in chronic wards in Taipei. Taiwan Yi Xue Hui Za Zhi. 1980;79(3):332-337.

243. Branchey MH, Branehey LB, Richardson MA. Effects of gradual decrease and discontinuation of neuroleptics on clinical condition and tardive dyskinesia [proceedings]. Psychopharmacol Bull. 1981;17(1):118-120.

244. Logothetis J, Paraschos A, Frangos E. Side effects in preventive maintenance therapy with neuroleptics with special emphasis on tardive dyskinesia. Bibl Psychiatr. 1981; 160:22-29.

245. Jeste DV, Wyatt RJ, Matthysse S. Neuroleptics and tardive dyskinesiaquo vadis? J Clin Psychopharmacol. 1982;2(5):303-304.

246. Christensen AV. Classification of neuroleptics: implications for tardive dyskinesia. Pol J Pharmacol Pharm. 1985;37(3):295-309.

247. Kovacic B, Ruffing D, Stanley M. Effect of neuroleptics and of potential new antipsychotic agents (MJ 13859-1 and MJ 13980-1) on a monkey model of tardive dyskinesia. J Neural Transm. 1986;65(1):39-49.

248. Mills MJ, Norquist GS, Shelton RC, et al. Consent and liability with neuroleptics: the problem of tardive dyskinesia. Int J Law Psychiatry. $1986 ; 8(2): 243-252$

249. Ellison G, See RE. Rats administered chronic neuroleptics develop oral movements which are similar in form to those in humans with tardive dyskinesia. Psychopharmacology (Berl). 1989;98(4):564-566.

250. Jeste DV, Krull AJ. Neuroleptics and tardive dyskinesia--a case of iatrogenesis. West J Med. 1990;153(5):560-561.

251. Bergen J, Kitchin R, Berry G. Predictors of the course of tardive dyskinesia in patients receiving neuroleptics. Biol Psychiatry. 1992;32(7):580-594.

252. Seigneurie AS, Sauvanaud F, Limosin F. [Prevention and treatment of tardive dyskinesia caused by antipsychotic drugs]. Encephale. 2016;42(3):248-254.

253. Van Wijnendaele R, Dagrada H, Leblanc P. [Tardive dyskinesia and second generation antipsychotics: a review of four cases]. Rev Med Brux. 2015;36(5):405-409.

254. O Brien A. Comparing the risk of tardive dyskinesia in older adults with first-generation and second-generation antipsychotics: a systematic review and meta-analysis. Int J Geriatr Psychiatry. 2015;31(7):683-693.

255. Nakajima S, Takeuchi H, Fervaha G, et al. Comparative efficacy between clozapine and other atypical antipsychotics on depressive symptoms in patients with schizophrenia: analysis of the CATIE phase 2E data. Schizophr Res. 2015;161(2-3):429-433.

256. Lerner PP, Miodownik C, Lerner V. Tardive dyskinesia (syndrome) Current concept and modern approaches to its management. Psychiatry Clin Neurosci. 2015;69(6):321-334.

257. Khouzam HR. Identification and management of tardive dyskinesia: A case series and literature review. Postgrad Med. 2015;127(7):726-737.

258. Jacobsen FM. Second-generation antipsychotics and tardive syndromes in affective illness: a public health problem with neuropsychiatric consequences. Am J Public Health. 2015;105(2):e10-e16. 
259. Gourzis P, Skokou M, Soubasi E, et al. Treatment of Tardive Dystonia Induced by Antipsychotics, Old and New. Clin Neuropharmacol. 2015;38(4):121-126.

260. Rangel Barajas C, Malik M, Vangveravong S, et al. Pharmacological modulation of abnormal involuntary DOI-induced head twitch response in male DBA/2J mice: I. Effects of D2/D3 and D2 dopamine receptor selective compounds. Neuropharmacology. 2014;83:18-27.

261. Kim J, Macmaster E, Schwartz TL. Tardive dyskinesia in patients treated with atypical antipsychotics: case series and brief review of etiologic and treatment considerations. Drugs Context. 2014;3:212259.

262. Waln O, Jankovic J . An update on tardive dyskinesia: from phenomenology to treatment. Tremor Other Hyperkinet Mov (N Y). 2013; $12: 3$.

263. Sakurai H, Bies RR, Stroup ST, et al. Dopamine D2 receptor occupancy and cognition in schizophrenia: analysis of the CATIE data. Schizophr Bull. 2013;39(3):564-574.

264. Moriguchi S, Bies RR, Remington G, et al. Estimated dopamine D(2) receptor occupancy and remission in schizophrenia: analysis of the CATIE data. J Clin Psychopharmacol. 2013;33(5):682-685.

265. Jankelowitz SK. Treatment of neurolept-induced tardive dyskinesia Neuropsychiatr Dis Treat. 2013;9:1371-1380.

266. Shortreed SM, Moodie EE. Estimating the optimal dynamic antipsychotic treatment regime: Evidence from the sequential multiple assignment randomized CATIE Schizophrenia Study. J R Stat Soc Ser C Appl Stat. 2012;61(4):577-599.

267. Nakamura M, Yasunaga H, Miyata H, et al. Mortality of neuroleptic malignant syndrome induced by typical and atypical antipsychotic drugs: a propensity-matched analysis from the Japanese Diagnosis Procedure Combination database. J Clin Psychiatry. 2012;73(4):427-430.

268. Kinon BJ, Kollack Walker S, Stauffer V, et al. Reduction in tardive dyskinesia symptoms during treatment with olanzapine or haloperidol. $J$ Clin Psychopharmacol. 2012; 32(3):420-422.

269. Karimi Khaledi M, Suda KJ, Shelton CM. Tardive dyskinesia after short-term treatment with oral metoclopramide in an adolescent. Int $J$ Clin Pharm. 2012;34(6):822-824.

270. Hermes E, Rosenheck R. Choice of randomization to clozapine versus other second generation antipsychotics in the CATIE schizophrenia trial. J Psychopharmacol. 2012; 26(9):1194-1200.

271. Hermes E, Rosenheck R. Predictors of antipsychotic dose changes in the CATIE schizophrenia trial. Psychiatry Res . 2012;199(1):1-7.

272. Chung AK. Atypical presentation of tardive dyskinesia associated with risperidone long-acting injection as maintenance treatment in bipolar affective disorder: a case report. Curr Drug Saf . 2012;7(1):21-23.

273. Xiang YT, Wang CY, Si TM, et al. Tardive dyskinesia in the treatment of schizophrenia: the findings of the Research on Asian Psychotropic Prescription Pattern (REAP) survey (2001 - 2009). Int J Clin Pharmacol Ther. 2011;49(6):382-387.
274. Wessels AM, Bies RR, Pollock BG, et al. Population pharmacokinetic modeling of ziprasidone in patients with schizophrenia from the CATIE study. J Clin Pharmacol . 2011;51(11):1587-1591.

275. Van Harten PN, Tenback DE. Tardive dyskinesia: clinical presentation and treatment. Int Rev Neurobiol. 2011;98:187-210.

276. Stroup TS, Appelbaum PS, Gu H, et al. Longitudinal consent-related abilities among research participants with schizophrenia: results from the CATIE study. Schizophr Res. 2011; 130(1-3): 47-52.

277. Peritogiannis V, Tsouli S. The emerging role of atypical antipsychotics in the treatment of tardive dyskinesia induced by other atypical antipsychotics. J Clin Psychiatry. 2011;72(7):1016-1017.

278. Lieberman JA, Stroup TS. The NIMH-CATIE Schizophrenia Study: what did we learn? Am J Psychiatry. 2011;168(8):770-775.

279. Levine SZ, Rabinowitz J, Ascher Svanum H, et al. Extent of attaining and maintaining symptom remission by antipsychotic medication in the treatment of chronic schizophrenia: evidence from the CATIE study. Schizophr Res. 2011;133(1-3):42-46.

280. Lai IC, Mo GH, Chen ML, et al. Analysis of genetic variations in the dopamine D1 receptor (DRD1) gene and antipsychotics-induced tardive dyskinesia in schizophrenia. Eur J Clin Pharmacol. 2011;67(4):383-388.

281. Kerfoot KE, Rosenheck RA, Petrakis IL, et al. Substance use and schizophrenia: adverse correlates in the CATIE study sample. Schizophr Res. 2011;132(2-3):177-182.

282. Hermes E, Nasrallah H, Davis V, et al. The association between weight change and symptom reduction in the CATIE schizophrenia trial. Schizophr Res. 2011;128(1-3):166-170.

283. Chakos M, Patel JK, Rosenheck R, et al. Concomitant psychotropic medication use during treatment of schizophrenia patients: longitudina results from the CATIE study. Clin Schizophr Relat Psychoses. 2011;5(3):124-134.

284. Caroff SN, Hurford I, Lybrand J, et al. Movement disorders induced by antipsychotic drugs: implications of the CATIE schizophrenia trial. Neurol Clin. 2011;29(1):127-148.

285. Caroff SN, Davis VG, Miller DD, et al. Treatment outcomes of patients with tardive dyskinesia and chronic schizophrenia. J Clin Psychiatry. 2011;72(3):295-303.

286. Shim JC, Kim YH, Kelly DL, et al. Tardive dyskinesia predicts prolactin response to buspirone challenge in people with schizophrenia. $J$ Neuropsychiatry Clin Neurosci. 2005;17(2):221-226.

287. Haleem DJ, Samad N, Haleem MA. Reversal of haloperidol-induced tardive vacuous chewing movements and supersensitive somatodendritic serotonergic response by buspirone in rats. Pharmacol Biochem Behav. 2007;87(1):115-121.

288. Ross CA. Buspirone in the treatment of tardive dyskinesia. Med Hypotheses. 1987;22(3):321-328. 